\title{
Optimal error analysis of MJO prediction associated with uncertainties in sea surface temperature over Indian Ocean
}

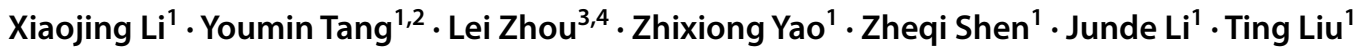

Received: 11 March 2019 / Accepted: 5 April 2020 / Published online: 10 April 2020

(c) The Author(s) 2020

\begin{abstract}
In this study, the predictability of the Madden-Julian Oscillation (MJO) is investigated using the coupled Community Earth System Model (CESM) and the climatically relevant singular vector (CSV) method. The CSV method is an ensemble-based strategy to calculate the optimal growth of the initial error on the climate scale. We focus on the CSV analysis of MJO initialized at phase II, facilitating the investigation of the effect of the initial errors of the sea surface temperature (SST) in the Indian Ocean on it. Six different MJO events are chosen as the study cases to ensure the robustness of the results. The results indicate that for all the study cases, the optimal perturbation structure of the SST, denoted by the leading mode of the singular vectors (SVs), is a meridional dipole-like pattern between the Bay of Bengal and the southern central Indian Ocean. The MJO signal tends to be more converged and significant in the Eastern Hemisphere while the model is perturbed by leading SV. The moist static energy analysis results indicate that the eastward propagation is much more evident in the terms of vertical advection and radiation flux than others. Therefore, the SV perturbation can strengthen and converge the MJO signal mostly by increasing the vertical advection of the moist static energy. Further, the sensitivity studies indicate that the structure of the leading SV is not sensitive to the initial states, which suggests that we might not need to calculate SVs for each initial time in constructing the ensemble prediction, significantly saving computational time in the operational forecast systems.
\end{abstract}

Keywords Optimal error analysis $\cdot$ Madden-Julian oscillation $\cdot$ CESM $\cdot$ Singular vector

\section{Introduction}

Much great effort has been made to improve weather forecasts on a timescale of several days (e.g., Wobus and Kalnay 1995; Weisman et al. 2010) and climate forecasts on seasonal-to-interannual timescales, which has achieved remarkable progress over the past decades (e.g., Bauer et al. 2015; Wang et al. 2009; Jin et al. 2008). Up to now, the prediction skill can reach over 0.9 at 5 days for weather forecast and 0.6

Youmin Tang

ytang@unbc.ca

1 State Key Laboratory of Satellite Ocean Environment Dynamics, Second Institute of Oceanography, Ministry of Natural Resources, Hangzhou, China

2 Environmental Science and Engineering, University of Northern British Columbia, Prince George, Canada

3 School of Oceanography, Shanghai Jiao Tong University, Shanghai, China

4 Southern Marine Science and Engineering Guangdong Laboratory (Zhuhai), Zhuhai, China at 12 month leads for El Niño-Southern Oscillation (ENSO) (e.g., Bauer et al. 2015; Barnston et al. 2017).

As the dominant intraseasonal variability in the tropics, the Madden-Julian Oscillation (MJO) plays an important role in connecting weather and climate variability. The MJO has extensive interactions with other components of the climate system, such as the ENSO (e.g., Tang and Yu 2008; Hoell et al. 2014), the Asian and Australian monsoon systems (e.g., Bai et al. 2013; Evans et al. 2014), and the extratropics (e.g., Moon et al. 2007; Lin et al. 2010). As a bridge of weather and climate variability prediction in the global climate system, skillful MJO prediction becomes immensely significant for the seamless forecast. Many efforts have been put into the study of MJO prediction using various statistical and dynamical models. However, so far, its skill is quite lower compared with the skills of weather and seasonal climate forecast. For example, if the correlation skill of 0.5 for MJO index prediction is defined as useful, it was found that the MJO can be predicted only around 30 days ahead by most of the present climate models (e.g., Fu et al. 2013; Wang et al. 2014; Lin et al. 2008; Ding et al. 2010, 2011). 
It is interesting to examine why the prediction skill of MJO is relatively low. Usually, the prediction uncertainty is a function of both the initial condition uncertainty and the model uncertainty (Palmer 2000). With the development of prediction models and assimilation schemes, the model and initial uncertainty may be alleviated. However, these errors cannot be eliminated completely, and they can exist in various forms-for example, computing truncation errors and observation errors. The potential predictability study usually ignores model errors and only considers initial uncertainty, i.e., it assumes the model to be perfect. The earth's climate system is a prototypical nonlinear system (Lorenz 1993; Palmer et al. 2014). The initial uncertainty in the small spatial scale can eventually induce errors in all other scales (Lorenz 1969; Leith and Kraichnan 1972). Therefore, the predictability cannot be extended limitlessly. That is, the predictability of climate variability is an intrinsic attribute, which is often known as intrinsic predictability or potential predictability. There have been several effort to provide predictability of weather forecast skill since 1980s (e.g., Kalnay and Dalcher 1987; Palmer and Tibaldi 1988). The intrinsic predictability provides an upper limit for the prediction skill achieved when both the model and initial states are perfect (Buizza 1997).

A key issue in the study of intrinsic predictability is to explore the optimal growth of the initial perturbation for the chosen model variables. By analyzing the evolution of the fast error growth, we can detect the physical processes responsible for the fast growth and improve the prediction skill by improving the representation of these key processes in the models. In particular, we can identify the most sensitive regions that contribute to the fastest growth of errors. By conducting appropriate observing experiments, i.e., increasing the observation frequency and density in the sensitive area, the prediction skill is expected to be improved. Further, the optimal initial perturbation is often used to construct efficient ensembles to sample the initial condition uncertainty (Palmer and Zanna 2013).

While optimal error growth analysis has been widely explored in weather forecast and seasonal climate prediction (e.g., Buizza 1995; Mu et al. 2007; Moore and Kleeman 1996), to our best knowledge, similar work for the prediction of MJO has not yet been reported. This is likely because of two reasons. First, it is still at an early stage to conduct the MJO prediction study, in particular its intrinsic predictability (e.g., Waliser et al. 2003; Kang et al. 2010; Kim et al. 2014). Second, the general circulation model (GCM), which is required to predict $\mathrm{MJO}$, contains multiple scale processes (e.g., Ahn et al. 2017). The traditional methods used to conduct optimal error analysis are often incapable of filtering noise and uncorrelated processes, thereby being unable to detect the appropriate physical process responsible for the growth of MJO errors (Kleeman et al. 2003).
In this study, we explored the optimal error analysis of MJO using the climatically relevant singular vector (CSV) method, which was developed by Kleeman et al. (2003). Different from the traditional SV (e.g., Palmer et al. 1994) and bred vector methods (e.g., Toth and Kalnay 1997), the CSV method uses an ensemble-based strategy to filter weather noise that is not often related to large-scale processes, e.g., MJO. The ensemble-based strategy is an efficient technique for the extraction of CSVs in the presence of weather noise (Kleeman et al. 2003). The CSV method has already been applied to study the optimal growth of errors for ENSO (Tang et al. 2006), seasonal climate prediction (Islam et al. 2016), and the decadal variability in the Atlantic Ocean (Hawkins and Sutton 2011).

As a first attempt, the chosen variable of perturbations in this study was the sea surface temperate (SST) in the Indian Ocean. The importance of the SST in the prediction of MJO has been discussed in several studies. Fu et al. (2008) found that among various SST configurations, the full atmosphere-ocean coupling, which generates an interactive SST, can result in the highest predictability of tropical intraseasonal oscillation, i.e., MJO, in boreal summer. Marshall et al. (2016) demonstrated the role of the anomalously high ocean SST in promoting the intensification of the MJO. In particular, in several studies (e.g., Vialard et al. 2008; Han et al. 2007), the SST in the Indian Ocean has been found to be closely related to the development and propagation of MJO. By analyzing multiple datasets, Yuan et al. (2014) found that the anomalous warm water in the southeastern Indian Ocean and the low-level westerly anomalies over the equatorial central Indian Ocean favor the eastward movement of the MJO. In this study, we attempted to identify the SST sensitive areas and their spatial structures that result in the fastest error growth of the MJO, through which we further analyzed the characteristics of the optimal perturbations and the possible dynamical mechanism responsible for the optimal error growth in the MJO prediction associated with SST uncertainties.

The content of this paper is organized as follows. Section 2 describes the model and the CSV method used. The sensitivity experiments related to the optimal perturbation modes (i.e., the leading singular vectors) are presented in Sect. 3. Section 4 presents an analysis of the leading singular vectors. Section 5 describes the investigation of the growth of the leading singular vectors. Finally, the conclusions and discussions are presented in Sect. 6.

\section{Model and method}

\subsection{Community earth system model}

The community earth system model (CESM) model, developed by the National Center for Atmospheric Research 
(NCAR), a fully coupled global climate model, was used in this study. It couples the atmosphere, ocean, land, landice, sea-ice, and river. Each individual module is a welldeveloped model including the atmospheric model CAM (Community Atmosphere Model), ocean model POP (Parallel Ocean Program), land model CLM (Community Land Model), sea-ice model CICE (The Los Alamos National Laboratory Sea-ice Model), land-ice model CISM (Glimmer Ice Sheet Model), and river model (River Transport Model). CESM supports numerous resolutions and component configurations, and each model component has multiple options to configure specific model physics and parameterizations.

The CESM's capability to simulate the MJO has been evaluated in Li et al. (2016), in which a systematic comparison was conducted among several experiments in terms of MJO characteristics and features, including the atmosphere model only (CAM4) and coupled experiments with two different atmospheric physics (CAM4 and CAM5) and resolutions $\left(1^{\circ}\right.$ and $\left.2^{\circ}\right)$. It was found that the coupled experiment with CAM5 atmosphere physics and $1^{\circ}$ horizontal resolution (hereinafter referred to as the CPL5_1d experiment) presents the most realistic propagation speed of the MJO. However, the coupled experiment with CAM4 atmosphere physics and $1^{\circ}$ horizontal resolution (CPL4_1d) shows the best representation of the MJO's strength. In particular, the CAM4 is much more computationally efficient. Therefore, in this study, the coupled configuration CPL4_1d is used. The coupled model spins up for 300 years until the equilibrium states are reached, from which the coupled model is integrated for another 10 years as the reference background used for optimal initial error analysis.

\subsection{MJO index and phase}

In the analysis of the error growth of the MJO prediction, we used the MJO index and phase following the method employed in Wheeler and Hendon (2004). The variables used are outgoing longwave radiation (OLR), zonal wind velocity at $850 \mathrm{hPa}$ (U850), and zonal wind velocity at $200 \mathrm{hPa}$ (U200). The first two empirical orthogonal functions (EOFs) were extracted in the multivariable EOFs analysis using the 10-year model integration (shown in Fig. 1). It is presented that there are strong negative OLR anomalies in the Indian Ocean for EOF1 and in the Maritime Continent and western Pacific for EOF2, both of which contribute to the eastward propagation of the intraseasonal convection. U850 and U200 have opposite phase in both modes. In addition, the deep convection (i.e., the large negative OLR anomalies) lags the large anomalies of zonal wind velocity. These MJO characteristics are consistent with those in previous studies (e.g., Subramanian et al. 2011; Li et al. 2016). Besides, the phase space diagram for the time period could be obtained by plotting the MJO index (square root of the

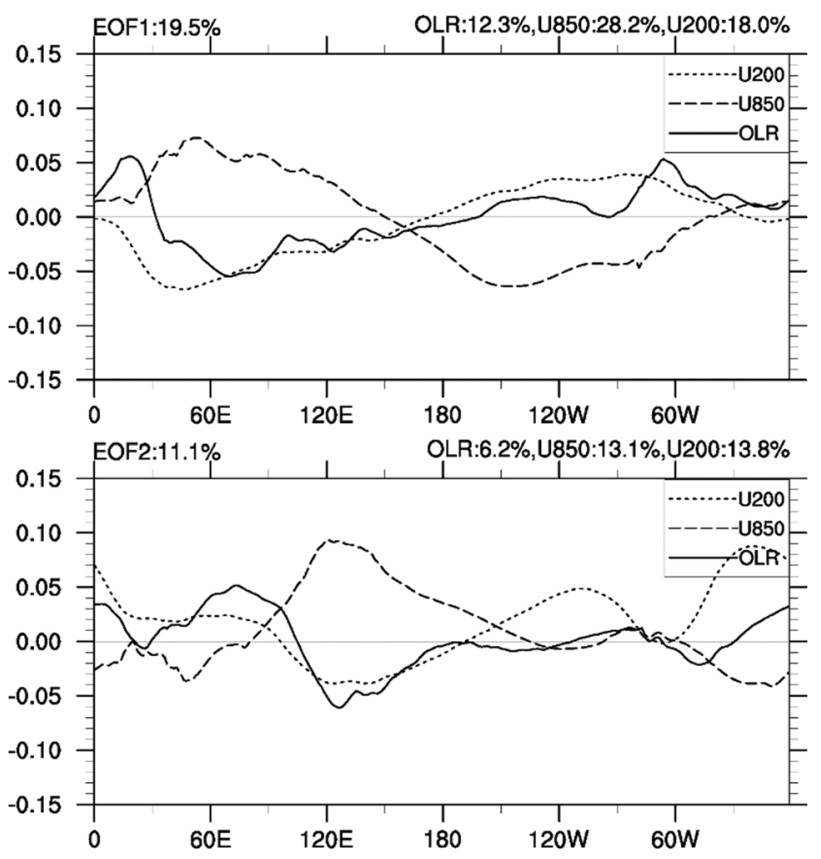

Fig. 1 First two leading EOFs by multivariate EOF analysis. Variables used in analysis are OLR, U850, U200 in 10-year model integration. Analysis method follows Wheeler and Hendon (2004). Variance explained by each mode is specified on top left of each panel, whereas variance explained by each variable in that mode is specified on top right of each panel

sum of the squares of first two principal components) in a two dimensional coordinate diagram based on the multivariable EOF analysis.

\subsection{Climatically relevant singular vectors method}

The formulation of the CSV method can be found in Kleeman et al. (2003) and Tang et al. (2006). For the convenience of the readers, we will briefly introduce it here.

A general dynamical system can be briefly represented as

$\mathbf{X}(t+\delta t)=\mathbf{F}[\mathbf{X}(t)]$

where $\mathbf{X}(t+\Delta t)$ is a vector representing the system state at time $t+\Delta t$ and $\mathbf{F}$ is a nonlinear operator. For a small perturbation $\mathbf{x}$ at time $t$, Eq. (1) can be written as

$\mathbf{X}(t+\Delta t))+\mathbf{x}(t+\Delta t)=\mathbf{F}[\mathbf{X}(t)+\mathbf{x}(t)]$

where $\mathbf{x}(t+\Delta t)$ represents the evolution of the perturbation $\mathbf{x}$ at time $t+\Delta t$.

Subtracting Eq. (1) from Eq. (2), we have

$\mathbf{x}(t+\Delta t)=\mathbf{F}[\mathbf{X}(t)+\mathbf{x}(t)]-\mathbf{F}[\mathbf{X}(t)]=\mathbf{R} \mathbf{x}(t)$

where $\mathbf{R}$ is the linear approximation of the nonlinear operator $\mathbf{F}$ with the reservation of the first-order derivative of $\mathbf{F}$ 
with respect to $\mathbf{X}$ at time $t$. It gives the time evolution of the dynamical system (1), usually called propagator.

The singular vectors of the propagator $\mathbf{R}$, corresponding to the errors that grow fastest over the interval time $\Delta t$, are the eigenvectors of ${ }_{\mathbf{R}}{ }^{\mathrm{T}}$, where ${ }_{\mathbf{R}}{ }^{\mathrm{T}}$ is the transpose of $\mathbf{R}$. Generally, the singular vector (denoted by $\mathbf{E}$ ) can be obtained using either of two methods: the eigenvector analysis of the ${ }_{\mathbf{R}}^{\mathrm{T}}{ }_{\mathbf{R}}^{\mathrm{T}}$ matrix:

$\mathbf{R}^{\mathrm{T}} \mathbf{R} \mathbf{E}=\lambda \mathbf{E}$

where $\mathbf{E}$ is the eigenvector of ${ }_{\mathbf{R}}{ }^{\mathrm{T}} \mathbf{R}$, or the singular value decomposition (SVD) analysis of $\mathbf{R}$ :

$\mathbf{R}(t, t+\Delta t)=\mathbf{U} \Sigma \mathbf{E}^{\prime}$

where $\mathbf{E}$ is the right singular vector of $\mathbf{R}, \mathbf{U}$ is the left singular vector, and $\boldsymbol{\Sigma}$ is the matrix of singular values of $\mathbf{R}$.

The final pattern, which represents the pattern after $\Delta_{t}$ time with the first singular vector as the initial perturbation, can be derived by applying the propagator $\mathbf{R}$ to the initial pattern $\mathbf{E}$, and, by combining Eq. (5), we have the following result:

$$
\mathbf{R E}=\mathbf{U} \boldsymbol{\Sigma} \mathbf{E}^{\prime} \mathbf{E}=\mathbf{U} \boldsymbol{\Sigma}
$$

Generally, the tangent and adjoint models of the original model are required for calculation in the conventional singular vector method. However, this is difficult for a complicated coupled model. Moreover, the small-scale weather noise needs to be filtered out for the climate scale prediction. Therefore, the calculation of $\mathbf{R}$ using an ensemble-based strategy described in Kleeman et al. (2003) is applied to address these concerns. The method of CSV is summarized below:

1. Select a perturbation variable (denoted by $\mathbf{V}_{p}$ ) at the initial time and a target variable (denoted by $\mathbf{V}_{t}$ ) used to measure forecast errors. By definition, the leading SV indicates what type of uncertainty in $\mathbf{V}_{p}$ can lead to the fastest error growth for the prediction of $\mathbf{V}_{t}$.

2. An ensemble of $\mathbf{M}$ forecasts with a leading time of 30 days is constructed by perturbing the initial $\mathbf{V}_{p}$ field with $\mathrm{M}$ "very small" random patterns whose amplitude is approximately $0.001{ }^{\circ} \mathrm{C}$. Subsequently, $\mathrm{M}$ results $\left(\boldsymbol{\Psi}_{0}{ }^{i}\right)$ of $\mathbf{V}_{t}$ are obtained after model integrations. The ensemble mean of $\boldsymbol{\Psi}_{0}{ }^{i}(t)$ is denoted by $\boldsymbol{\Psi}_{0}{ }^{i}(t)$, $i=1,2,3, \ldots, M$.

3. Each leading correlation EOF mode $\mathbf{e}_{j}$ $(j=1,2,3, \ldots, \mathbf{N})$ of $\mathbf{V}_{p}$ is added (with a multiplication factor of 0.1 to ensure linearity) to the ensemble initial conditions described in step ii), and a new ensemble of M forecasts $\left(\Psi_{\mathrm{j}}{ }^{i}, i=1,2,3, \ldots, M\right)$ is produced. The corresponding ensemble mean of $\boldsymbol{\Psi}_{j}^{i}$ is denoted by $\boldsymbol{\Psi}_{j}^{i}(t)$, $i=1,2,3, \ldots, M$.

4. The difference between the ensembles obtained in steps 2 and 3 can be considered as the error growth $\mathbf{x}(t+\Delta t)$ in Eq. (3), where $\mathbf{e}$ is the initial error $\mathbf{x}(t)$. A reduced-state space matrix version $\mathbf{r}_{i j}$ of the propagator $\mathbf{R}$ is then obtained. Mathematically it can be represented as:

$$
\begin{aligned}
\Delta \overline{\boldsymbol{\Psi}(t)}= & \overline{\Psi_{j}^{i}(t)}-\overline{\boldsymbol{\Psi}_{0}^{i}(t)}=\mathbf{R E}=\sum_{j=1}^{\mathrm{N}} \mathbf{r}_{i j} \mathbf{e}_{i j} \\
& +\operatorname{residual}(i=1,2,3, \ldots \mathrm{M}, j=1,2,3, \ldots, \mathrm{N})
\end{aligned}
$$

The residual in Eq. (7) is generally very small and can be ignored (Kleeman et al. 2003). The climatically relevant singular vectors are thus obtained by SVD analysis of $\mathbf{R}$ as aforementioned. These singular vectors are then projected back to the real $\mathbf{V}_{p}$ space using the EOF basis vector expansion.

It is worth noting that the EOF analysis should be conducted using the correlation matrix as opposed to the traditional covariance matrix in order to address the spatial coherence of initial perturbation (Kleeman et al. 2003). It is equivalent to the traditional EOF analysis using the normalized sea surface temperature anomaly. In a non-normal dynamical system, there is often a big difference in the spatial structure between regular EOFs and singular vectors (Farrell and Ioannou 2001). Consequently, the suitable reduced-state space for singular vectors using the traditional EOF expansion bases often causes problems. The use of correlation EOFs is found to be a means to recover the correct singular vector structures (Moore and Kleeman 2001). The point of using correlation EOFs is that the structures that may be small in amplitude but have strong large-scale spatial and temporal coherency are emphasized. It should be noted that the correlation EOF analysis used in the present study is different from the canonical correlation analysis (CCA). The latter defines coordinate systems that optimally describe the cross covariance between two different datasets (Barnett and Preisendorfer 1987), whereas the former defines an orthogonal coordinate system that optimally describes variance in a single dataset normalized by its standard deviation in order to emphasize the spatial and temporal coherency.

In this study, we focused on the effects of the initial SST uncertainties on the MJO prediction, i.e., we selected SST here as the perturbation variable $\left(\mathbf{V}_{p}\right)$ at the initial time. Considering that the OLR is widely used as a good indicator of convective activity, which is the primary feature of the MJO 
(e.g., Subramanian et al. 2011), we chose it as the prediction target variable $\mathbf{V}_{t}$.

\section{Sensitivity of leading singular vector to some parameters}

As discussed in Sect. 2, there are two parameters that must be determined for the CSV calculation. One is the number of leading correlation EOF modes, denoted by $\mathrm{N}$ here, and the other is the ensemble size, denoted by M. Therefore, the sensitivity of the optimal perturbation patterns to these parameters must be examined for a reliable and robust analysis. In this section, we examine these two issues.

\subsection{Number of leading correlation EOF modes}

First, we examined the robustness of the singular vectors with respect to the number of leading correlation EOFs modes $(\mathrm{N})$ used for calculation. We conducted a CSV analysis using various values of $\mathrm{N}$, and the patterns of the leading singular vectors and their corresponding singular values are shown in Fig. 2. Figure 2a shows the pattern of the leading $\mathrm{SV}$ for $\mathrm{N}=2$, characterized by a northeast-southwest dipole mode, whereas the pattern becomes a meridional dipole mode and remains stable for $\mathrm{N}>3$. The singular values increased as $\mathrm{N}$ increased, but the increasing rate declined gradually (Fig. 2b). Figure 2 indicates that the leading SV pattern can converge to a stable structure when the number of EOF modes used exceeds 3. Thus, we choose $\mathrm{N}=5$ to conduct the CSV analysis in this study for a conservative
Fig. 2 First leading singular vectors (a) and corresponding singular values (b) for using different number of EOFs in calculation. Number specified between each two data columns is increase rate of latter value by former one (a)
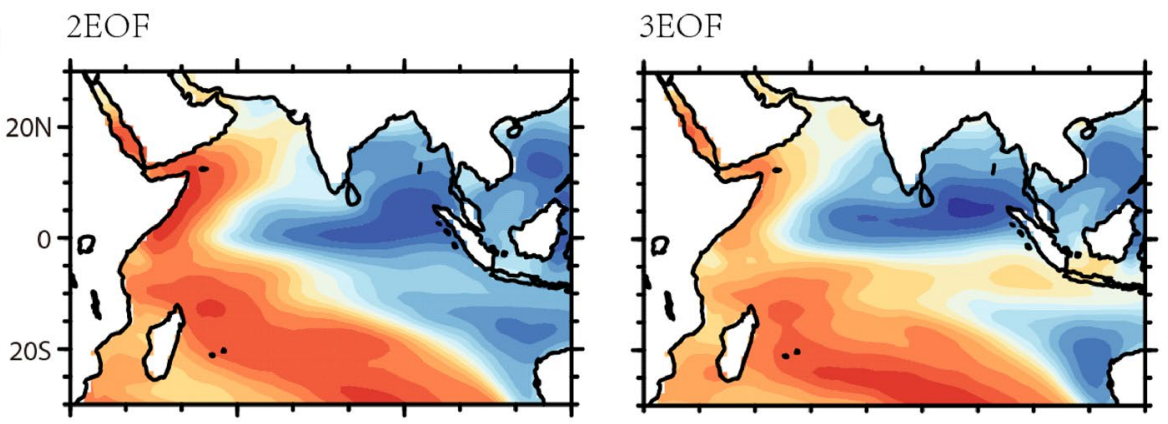

\section{$4 \mathrm{EOF}$}

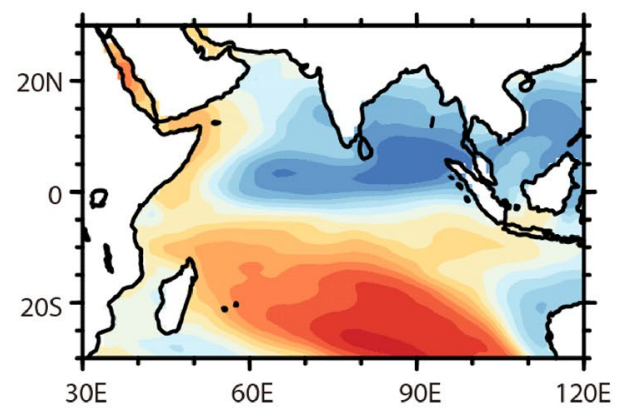

$5 \mathrm{EOF}$

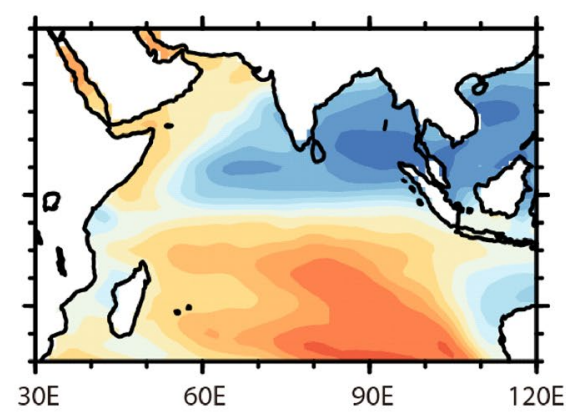

$-0.8$
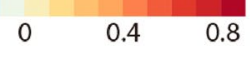

(b)

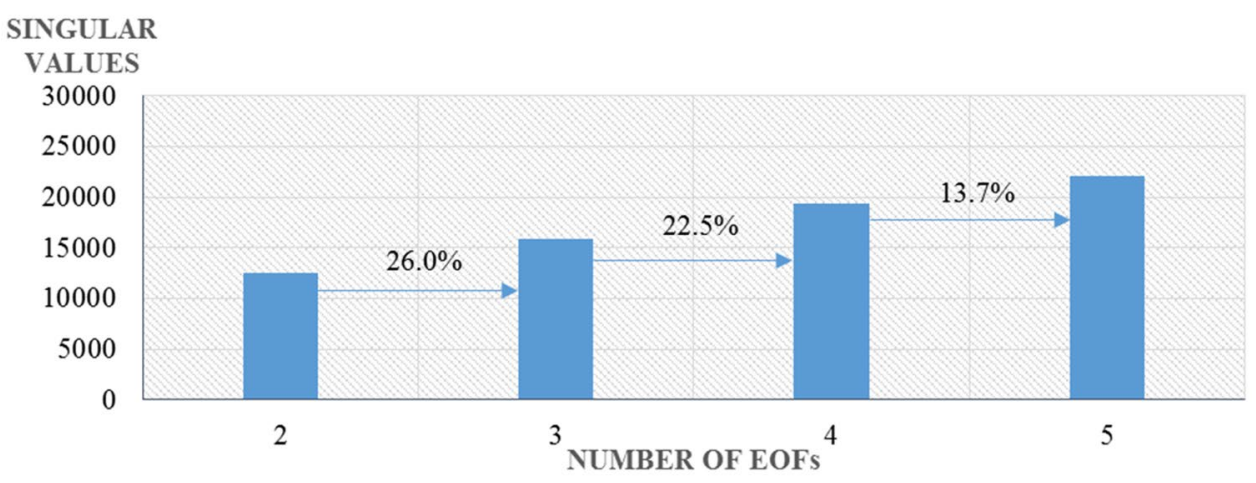


Fig. 3 Diagram of singular values (a) and singular vectors (b) with number of ensemble members for uncertainties in Indian Ocean (a)

SINGLAR VALUE

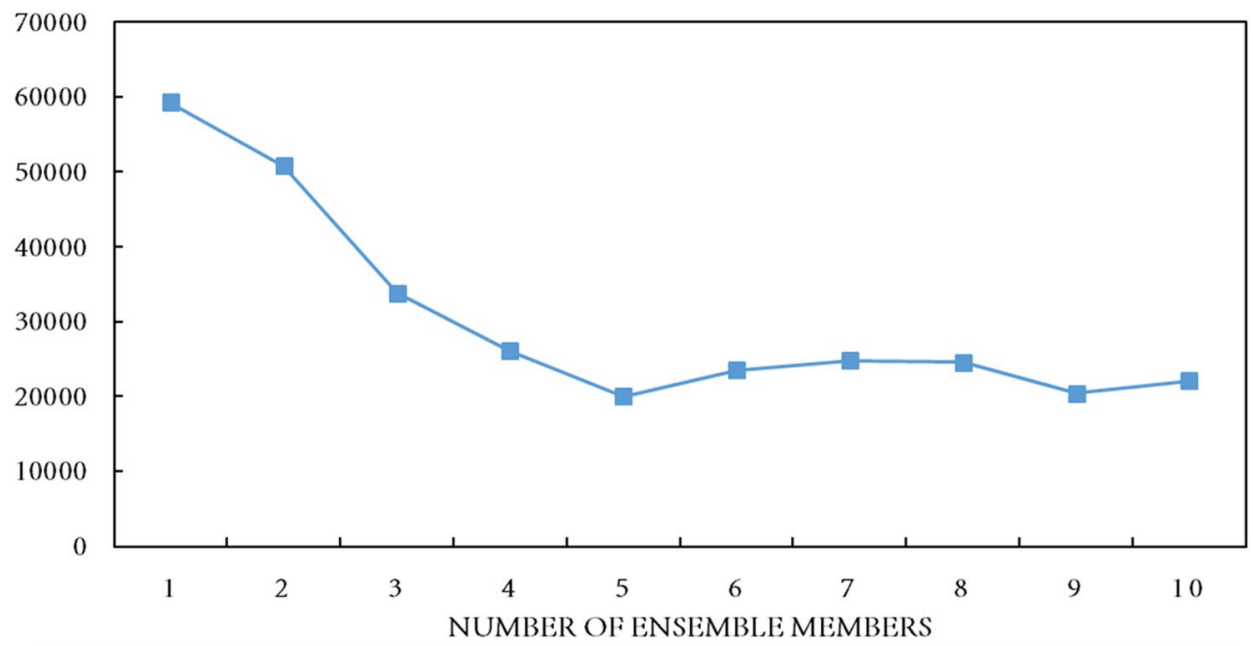

(b) (b) $M=5$

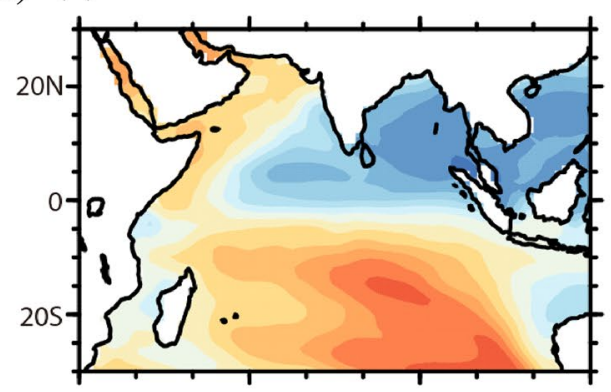

$\mathrm{M}=6$

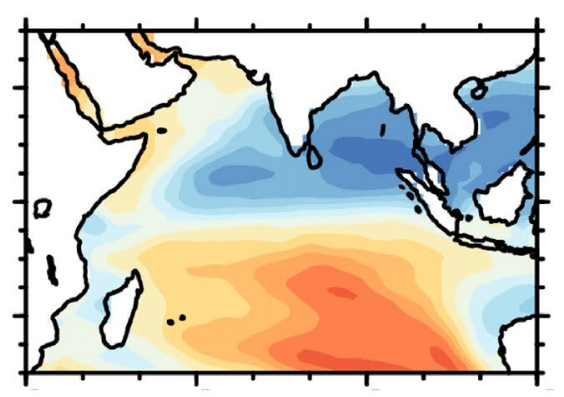

$\mathrm{M}=7$

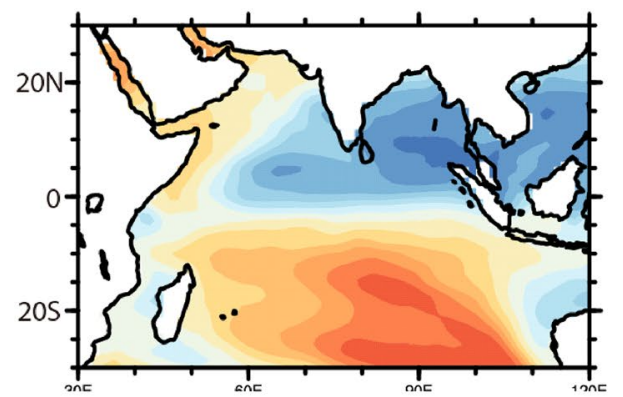

$\mathrm{M}=8$

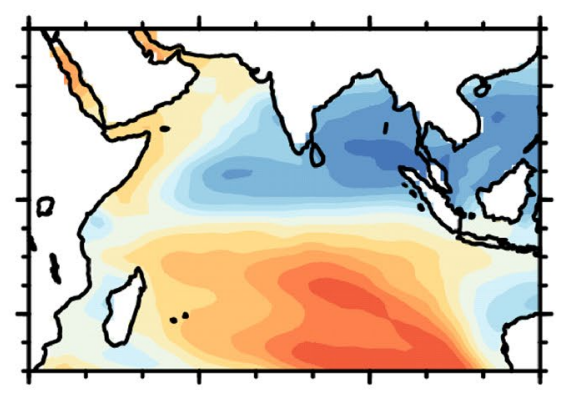

$\mathrm{M}=10$
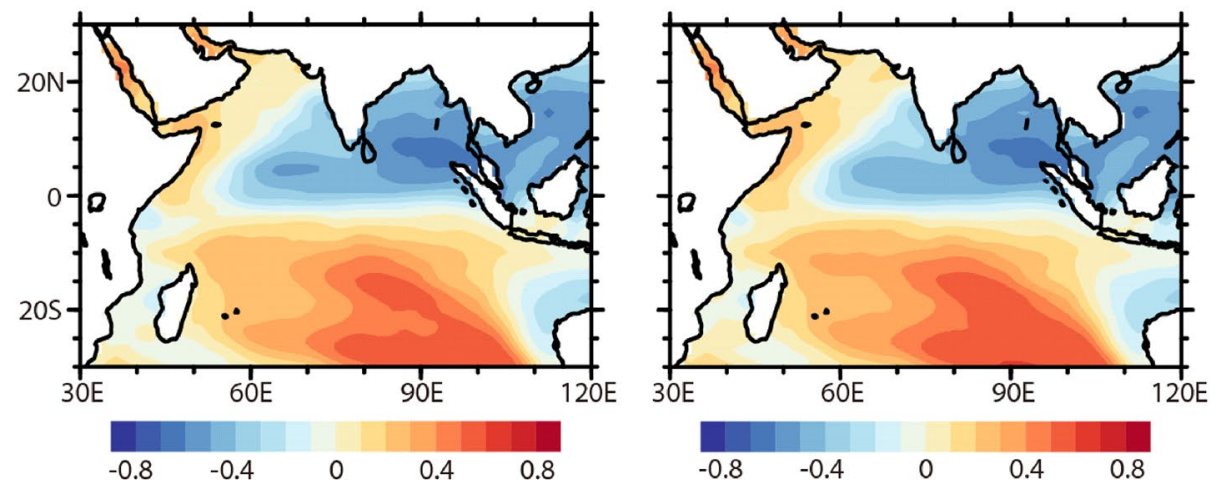
consideration. It should be noted that the final patterns, obtained using the leading SV mode applied to the propagator matrix, also indicate convergence when the number of EOF modes used exceeds 3.

\subsection{Ensemble size $M$}

The ensemble size is the other important factor that affects the CSV results. Technically, as the number of ensemble members increases, the accuracy of the results increases as well. However, it is not realistic to use a very large ensemble size owing to computational limitations. Therefore, it is necessary to determine the appropriate size to ensure reliable and robust results with an affordable computational source.

The singular values corresponding to the leading singular vectors for various ensemble sizes are specified in Fig. 3a. It is depicted that the singular values converge when the ensemble size exceeds 5 . The singular vectors also tend to converge to a stable pattern when the ensemble size is larger than 5, which is depicted in Fig. 3b. Accordingly, to ensure a robust result, we choose 10 members to calculate singular vectors in the next section.

\subsection{Validation of leading SV}

The CSV method is a linear approximation approach. Therefore, it is essential to verify its suitability and accuracy, i.e., to examine whether the final pattern obtained by the CSV linear approximation method can well represent the realistic evolution of the leading singular vectors under the original CESM.

To verify this, the CESM is integrated twice, once from the initial condition superimposed with the leading singular vectors, and the other only from the initial condition. The difference between these two integrations, denoted by $\Delta \boldsymbol{\Psi}$, indicates the error growth of the singular vectors obtained by the nonlinear model. Subsequently, the validation can be implemented by comparing this result with the final patterns obtained directly from the linear CSV method.

The final pattern from the linear CSV method, i.e., after applying the propagator $\mathbf{R}$ to the leading singular vectors, is shown in Fig. 4a, b) illustrates the difference $\Delta \Psi$. It is shown that $\Delta \boldsymbol{\Psi}$ has a structure very similar to the final pattern obtained from the linear approximation. Their spatial correlation coefficient is approximately 0.74 , as denoted in the upper right corner of the bottom panel. Although there are more or less discrepancies, their general features resemble each other reasonably well, suggesting that the CSV method is a good approximation method and can obtain the realistic optimal perturbation.

\section{Optimal perturbation pattern and optimal error growth}

In this section, we explore the optimal error growth of the MJO prediction associated with the uncertainties in SST by applying the CSV method. As discussed in Sect. 2, the leading correlation EOFs of SSTA over the Indian Ocean (IO) should be obtained to construct the ensemble run. The 10-year coupled experiment daily output data from CPL4_1d is used to calculate the leading EOFs. The first and second leading EOFs account for $23.0 \%$ and $21.4 \%$ of the total variance, respectively.

\subsection{Optimal perturbation patterns (leading SVs)}

In this study, we perturbed the SST of the Indian Ocean where the MJO originates, i.e., the initial perturbation occurs at the MJO onset phase. To obtain robust results, we
Fig. 4 OLR anomalies obtained from linear CSV method (top) and nonlinear numerical model integration (bottom). Their spatial correlation coefficient is approximately 0.74 , as specified on top right of bottom panel. This model is integrated twice for 30 days, once under initial condition superimposed with singular vectors and once under original initial condition. Nonlinear result is obtained from difference between these two integrations

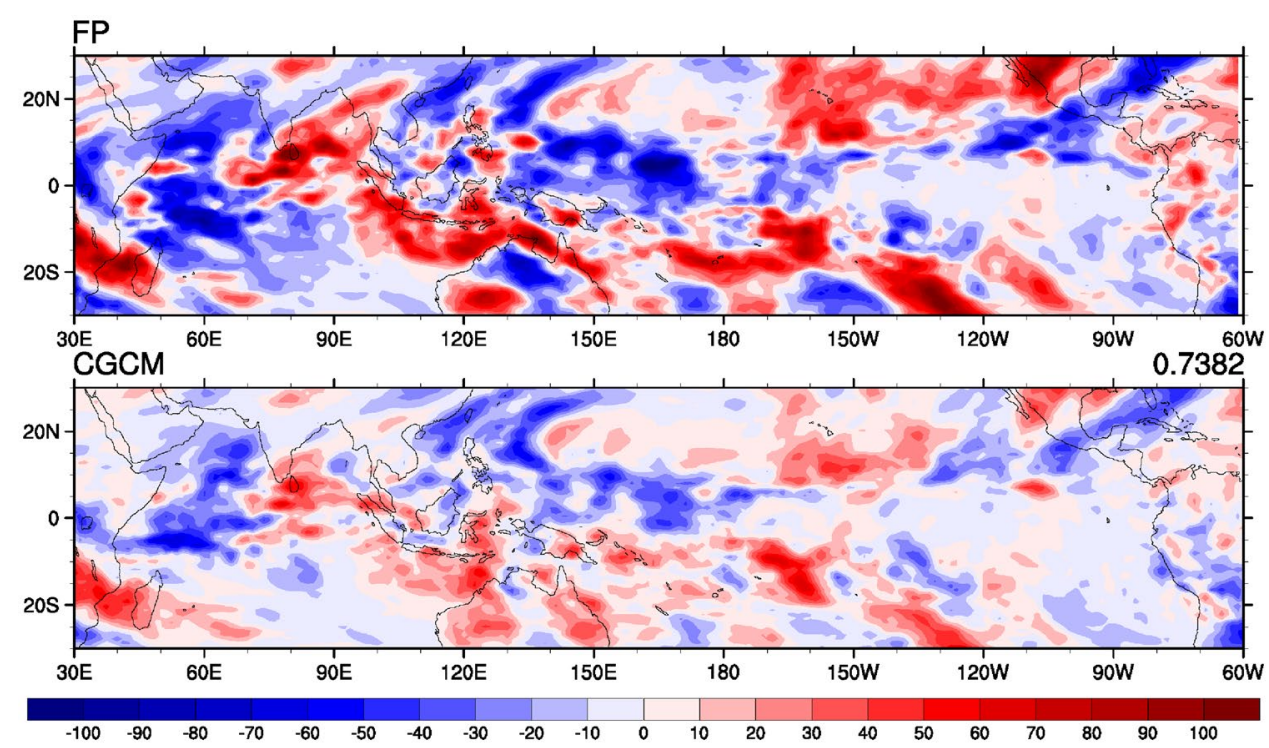


Table 1 Details of selected events and corresponding singular values

\begin{tabular}{lll}
\hline Event number & $\begin{array}{l}\text { Initial time in 10-year simulation } \\
\text { output }\end{array}$ & $\begin{array}{l}\text { Singular } \\
\text { value } \\
\left(\times 10^{4}\right)\end{array}$ \\
\hline 1 & November 4, 1st year & 2.21 \\
2 & February 19, 2nd year & 1.36 \\
3 & June 23, 2nd year & 1.84 \\
4 & January 23, 4th year & 2.59 \\
5 & June 6, 7th year & 1.04 \\
6 & January 5, 10th year & 1.47 \\
\hline
\end{tabular}

performed a CSV analysis for $6 \mathrm{MJO}$ events in which the initial perturbation always occurred during the onset period. Based on the 10-year output data of the coupled experiments CPL4_1d, the six MJO events are chosen as presented in Table 1, and the phase space diagrams for these six events are shown in Fig. 5. Each panel displays the MJO evolution of 45 days, basically spanning the entire cycle of the chosen MJO events. Each month is indicated by a separate color line. The numbers correspond to the day of the month. We chose these six events for two reasons: (1) the MJO regularly starts with active convection in the west Indian Ocean. However, some events may start in Indonesia or even in the western Pacific (Matthews 2008). We only focus on the regular or conventional type of MJO in this study, i.e., those that start in the Indian Ocean and propagate to the Pacific Ocean through the Maritime Continent (MC), and their cycles last for approximately 30 days. (2) The SSTAs, which are used as the background onto which the initial perturbations superimpose, are different for each chosen MJO event; thus, the sensitivity of the fastest growth of errors to the background can be explored. It was found that the fastest growth of errors is not sensitive to the background for ENSO prediction (e.g., Tang et al. 2006). Thus, it is interesting to explore this issue for the MJO prediction. Figure 6 presents the background SST anomalies over the IO at the initial time for the six events. As stated, their patterns are indeed quite different. For example, Case 2 identifies strong positive SSTA around the Sumatra Island, whereas Case 5 identifies strong negative SSTA in the central IO.

The results of the first leading singular vector for all the cases are presented in Fig. 7. The large values of the singular vectors are mainly located in the Bay of Bengal and the south central IO [around $\left(25^{\circ} \mathrm{S}, 90^{\circ} \mathrm{E}\right)$ ], which is a meridional dipole-like pattern. The singular vectors of all cases resemble each other, although the background SSTA patterns are very different from each other at the initial time, suggesting that the first leading singular vectors are not sensitive to the initial SSTA background states for the MJO prediction.
Fig. 5 Phase-space diagrams for six chosen events. Each panel displays MJO phase for 45 days spanning entire cycle of chosen MJO event. Each month is indicated by separate color line. Numbers correspond to day of month

\subsection{Growth of SVs}

For convenience, the forecast experiment under the original SST initial condition is denoted as "experiment woSV" below, and the experiment under the SST initial condition superimposed with the singular vectors is referred to as "experiment wSV". Generally, the MJO is described by its intraseasonal period and eastward propagation characteristic. Thus, we represent the growth of the SVs by the intraseasonal OLR development indicating their intraseasonal characteristics in this section.

Figure 8 depicts the Hovmoller diagram of intraseasonal OLR anomalies for the experiments woSV and experiments wSV for all cases. The OLR data is a proxy of the deep convection (Arkin and Ardanuy 1989). Therefore, the intraseasonal negative OLR anomalies are often used to characterize convective anomalies related to the MJO (e.g., Matthews 2000; Kiladis et al. 2005). The contours describe the anomalies $\pm 20 \mathrm{~W} \cdot \mathrm{m}^{-2}$. The initial time is at phase II located in the Indian Ocean. As time goes on, the MJO propagates eastward through the Maritime Continent and Western Pacific to the Western Hemisphere. In experiments woSV, the enhanced deep convection (indicated by the negative intraseasonal OLR anomalies) originated from approximately $60^{\circ} \mathrm{E}$ in the Indian Ocean at the initial time and then propagated eastward through the Maritime Continent and western Pacific Ocean for all cases, although the strength and location differed from each other owing to their uniqueness. The strength of the convection decreased gradually and finally disappeared after crossing the date line. Generally, with SV perturbation, the convection displayed more converged and strengthened characteristics in the Eastern Hemisphere, particularly after crossing $120^{\circ} \mathrm{E}$ for all cases. A comparison of the experiments woSV and wSV for all cases reveals that perturbation by singular vectors led to a more converged and significant MJO signal in the Eastern Hemisphere.

\section{Possible mechanism for optimal error growth}

In this section, we describe the dominant mechanism responsible for the SV growth, which helps us to understand the MJO dynamics as well.

In the earlier theoretical and modeling studies, the MJO is thought to be driven by feedback involving surface turbulent fluxes (Neelin et al. 1987) or radiative fluxes (Raymond 
(a) MJO Phase: 15S-15N: 1011101-1011206
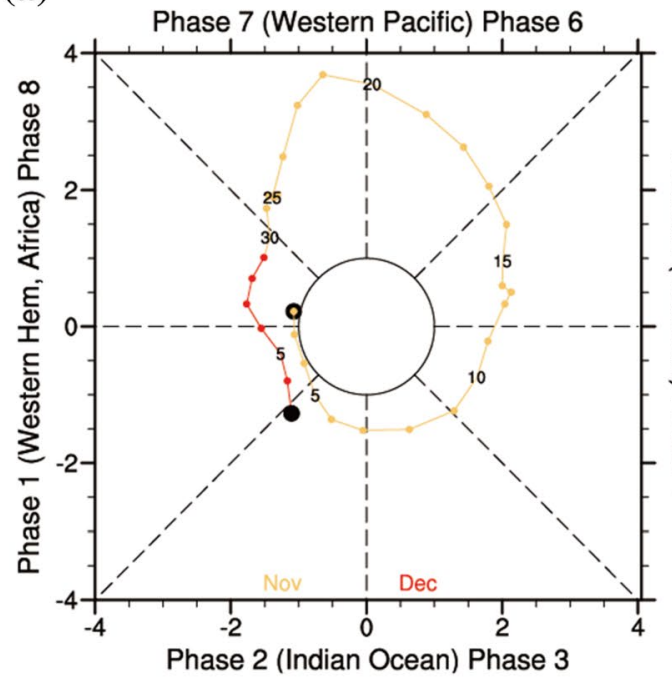

(c) MJO Phase: 15S-15N: 1020620-1020725
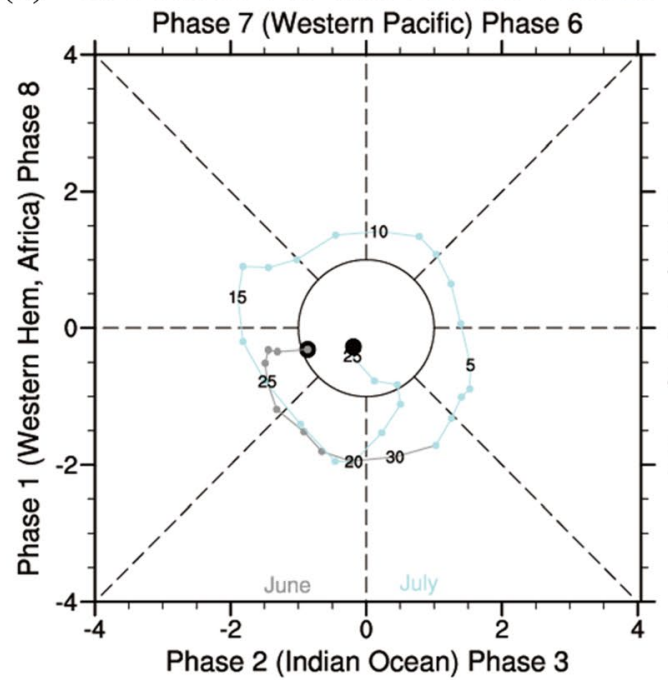

(e) MJO Phase: $15 \mathrm{~S}-15 \mathrm{~N}$ : $1070603-1070708$
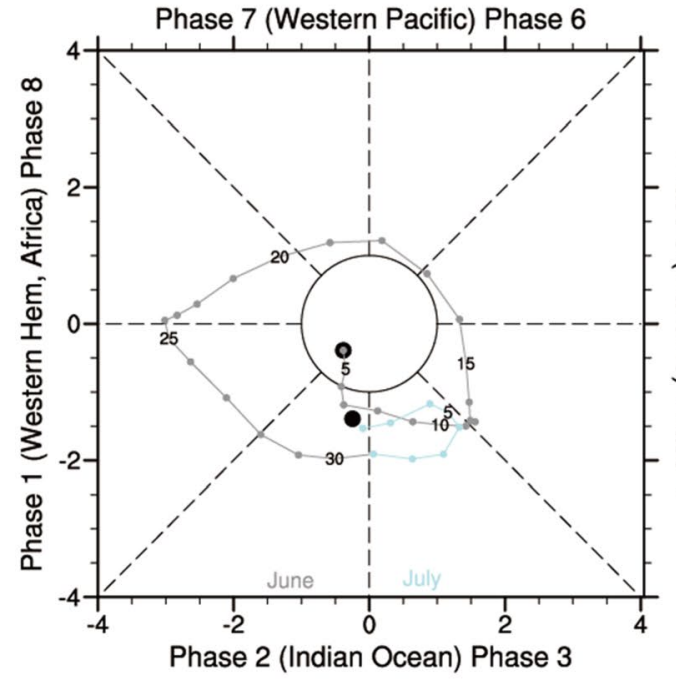

(b) MJO Phase: 15S-15N: 1020216-1020323

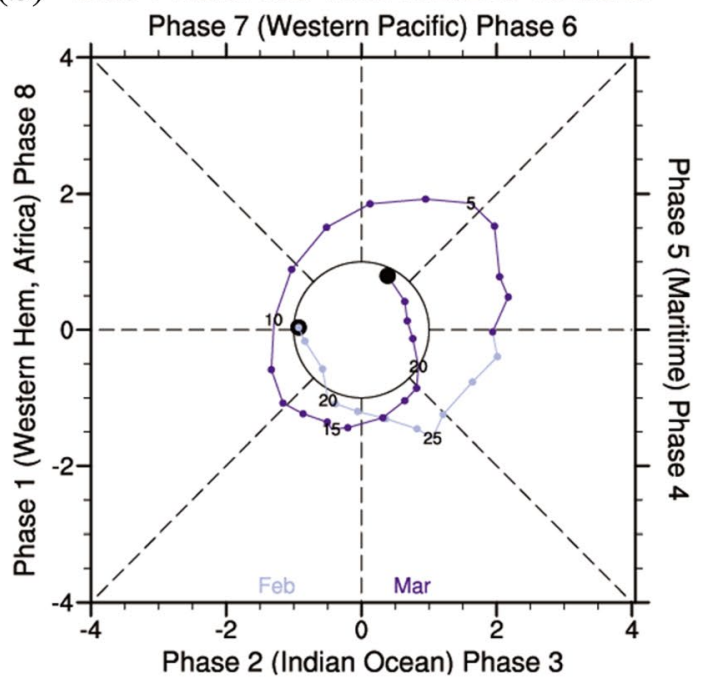

(d) MJO Phase: 15S-15N: 1040120-1040225

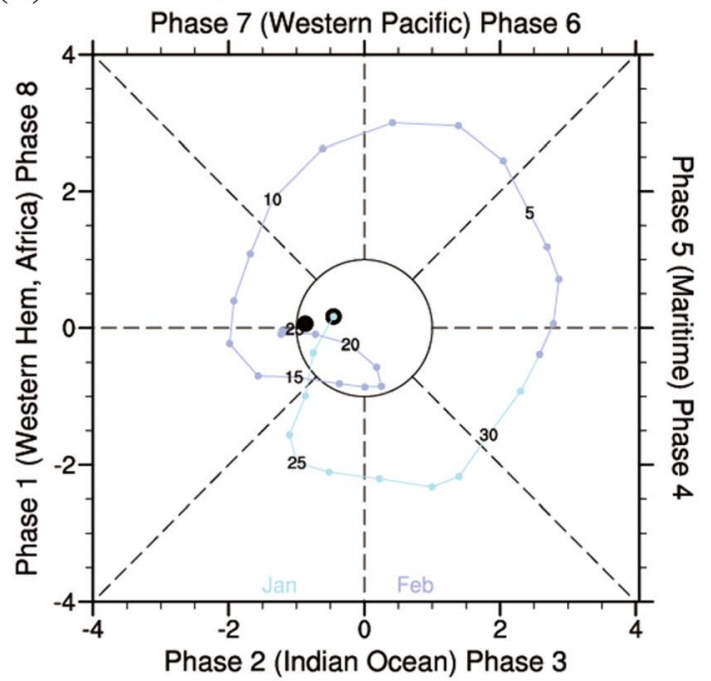

(f) MJO Phase: 15S-15N: 1100102-1100206

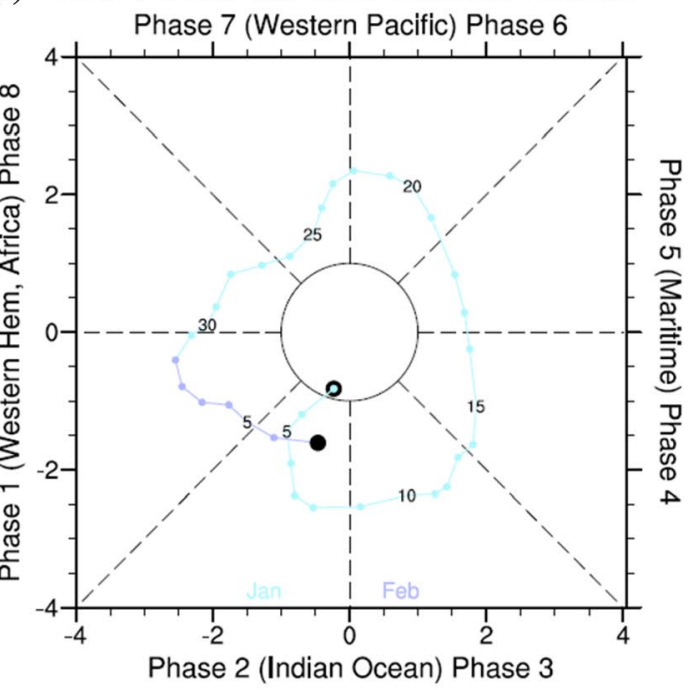




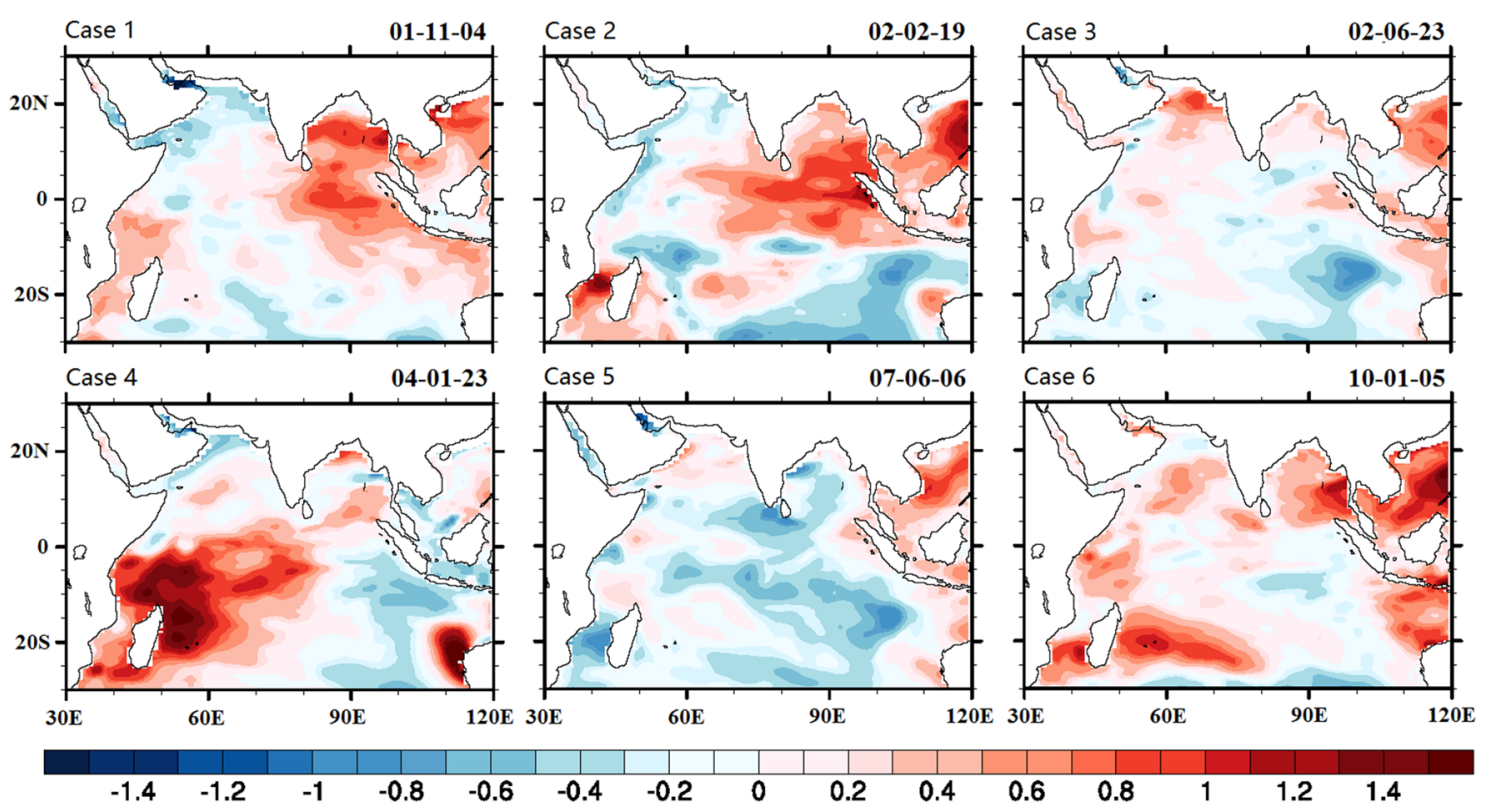

Fig. 6 Background SST anomaly at initial time for six study cases in Indian Ocean. Dates on top right of each panel represent initial time of each event in 10-year simulation output
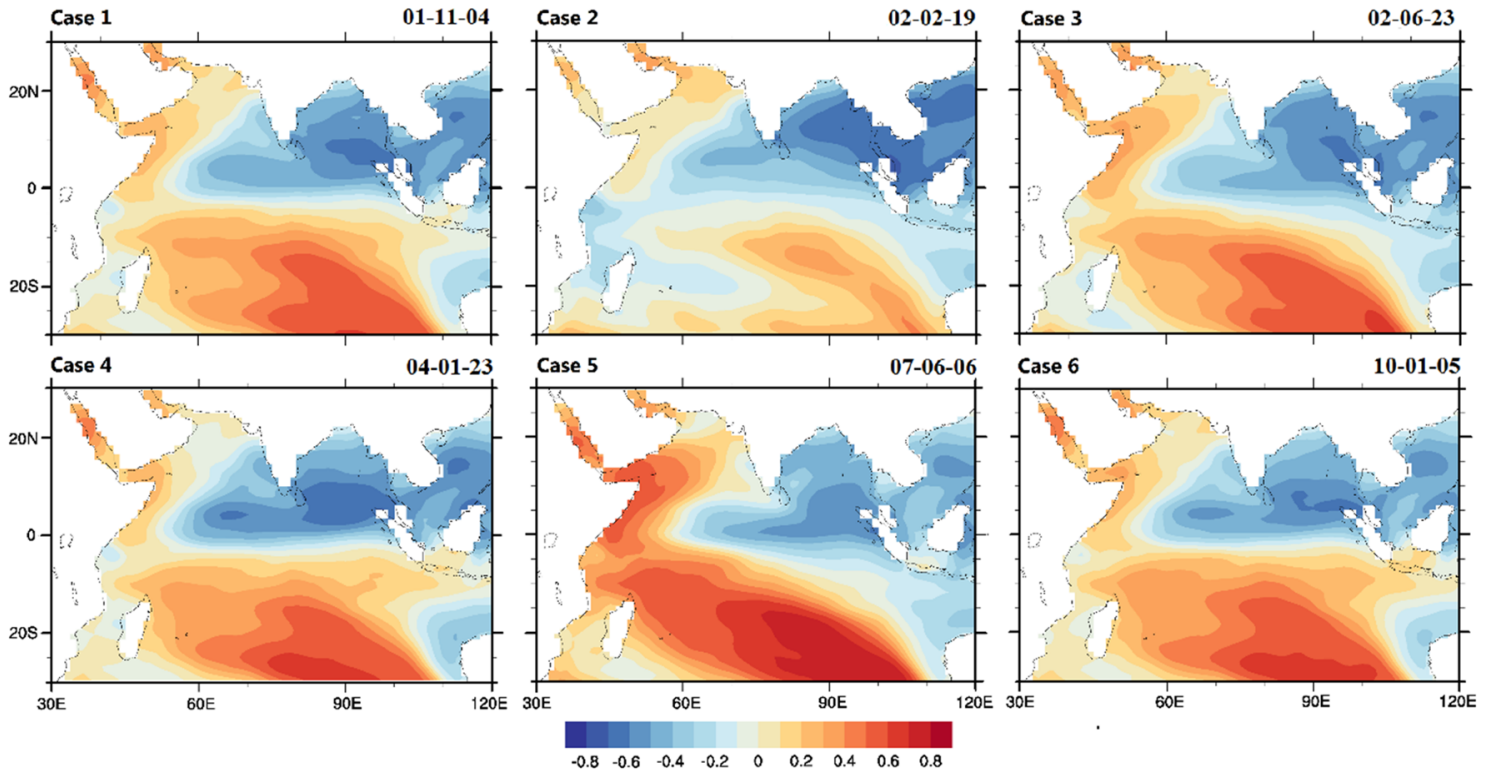

Fig. 7 Spatial pattern of leading singular vectors for six cases over Indian Ocean 

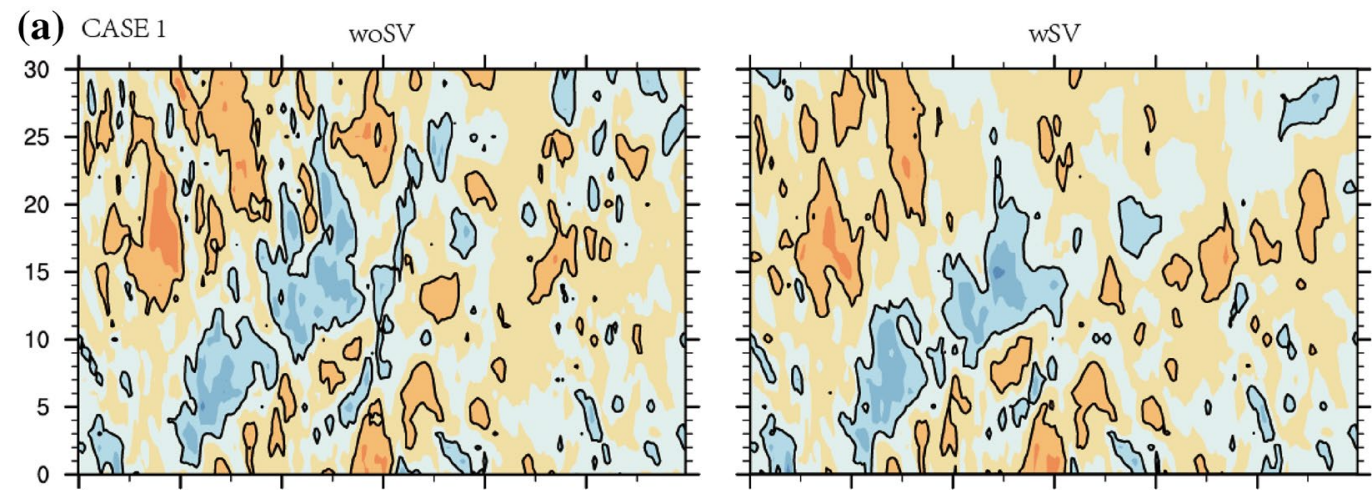

(b) CASE 2
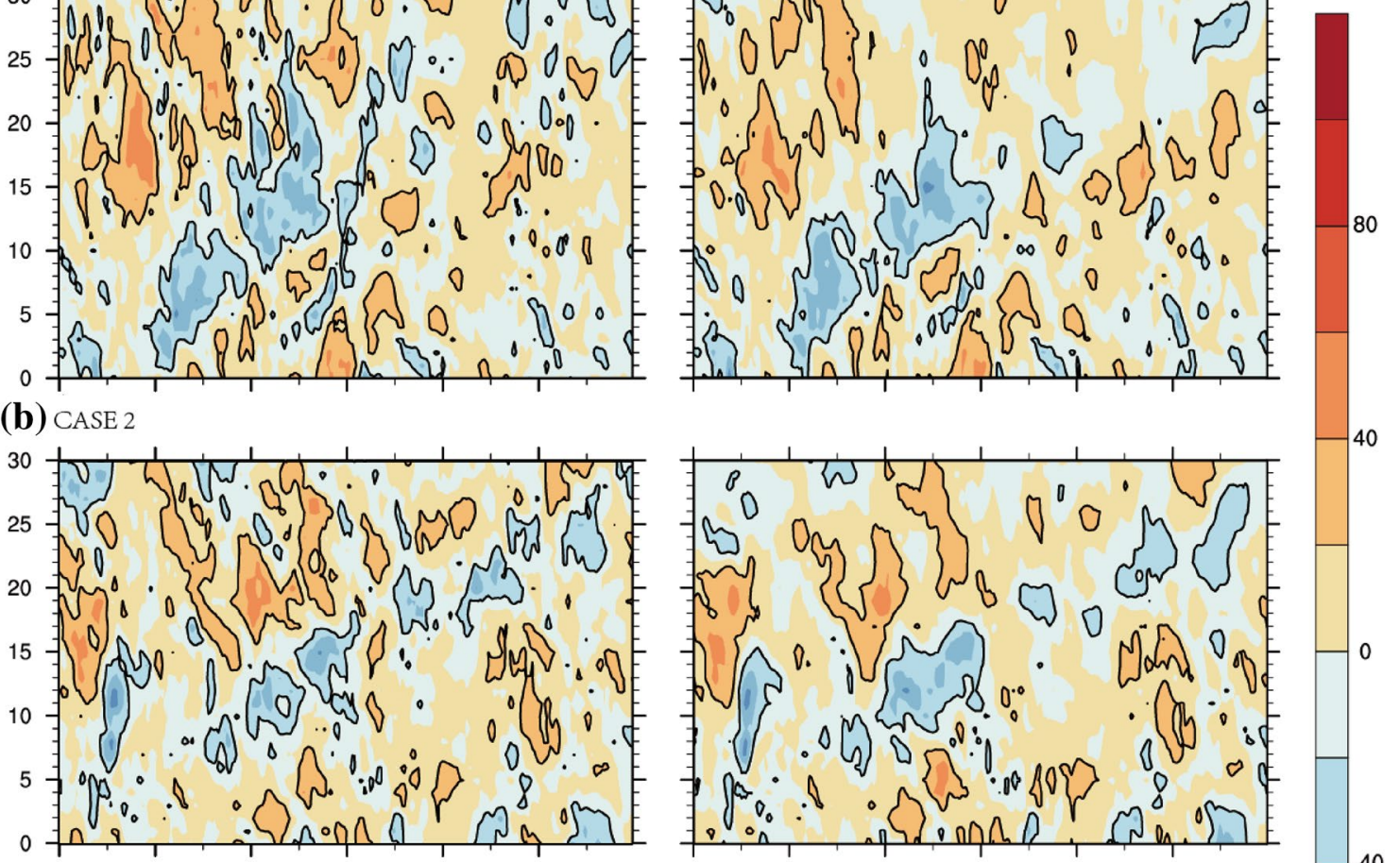

(c) CASE 3
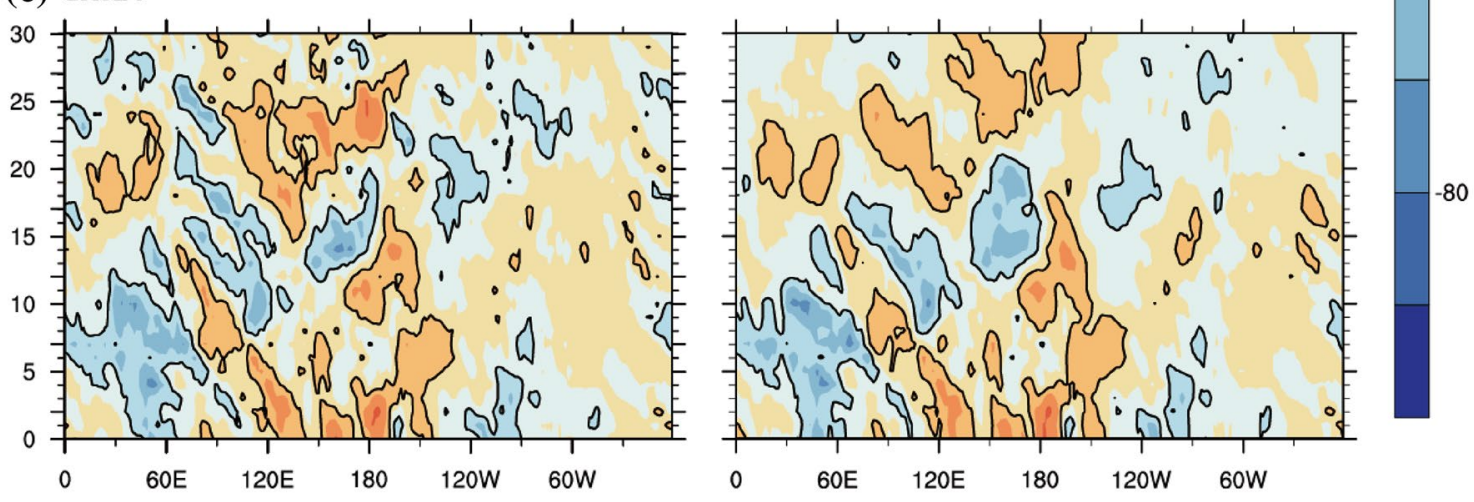

Fig. 8 Intraseasonal OLR anomaly $\left(\mathrm{W} \mathrm{m}^{-2}\right)$ development process of original simulation (left), and simulation under initial SST condition superimposed with leading singular vectors in IO (right). Anomalies above $20 \mathrm{~W} \mathrm{~m}^{-2}$ and below $-20 \mathrm{~W} \mathrm{~m}^{-2}$ are contoured

2001). As these processes are sources and sinks of the column-integrated moist static energy (MSE) or moist entropy, it is useful to view the MJO through the column integrated budgets of these conserved variables. In several MJO studies, the MJO dynamics are regulated by a recharge-discharge cycle (e.g., Maloney 2009) of the MSE. A buildup of the column-integrated MSE occurs within low-level easterly anomalies in advance of the MJO deep convection, and the MSE is discharged during and after periods of strong MJO convective and stratiform heating when westerly anomalies occur (Sobel et al. 2014). The strongest MSE anomalies peak in the lower troposphere and are primarily regulated by the anomalies of specific humidity. Some studies (e.g.,
Sobel and Gildor 2003; Agudelo et al. 2006) have identified a buildup of ocean heat content occurring before the onset of the MJO deep convection, and anomalous heat content being discharged into the atmosphere during the MJO convective phase. In Maloney's study (2009), the leading terms in the column-integrated intraseasonal MSE budget are horizontal advection and surface latent heat flux, where the latent heat flux is dominated by the wind-driven component. Horizontal advection causes the recharge (discharge) of the MSE within regions of anomalous equatorial lower-tropospheric easterly (westerly) anomalies, with the meridional component of the moisture advection dominating the MSE budget near $850 \mathrm{hPa}$. The latent heat flux anomalies oppose the 
(d) $\operatorname{CASE} 4$

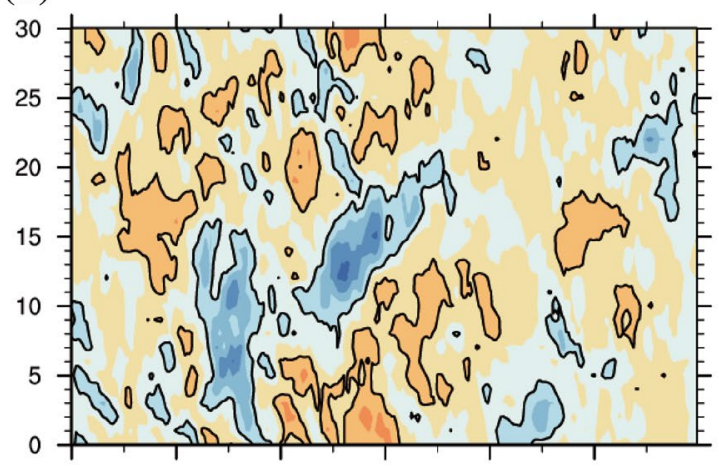

(e) CASE 5

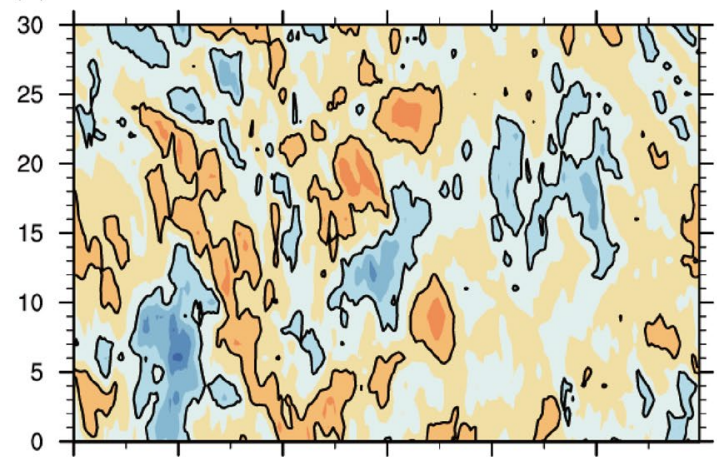

(f) CASE 6

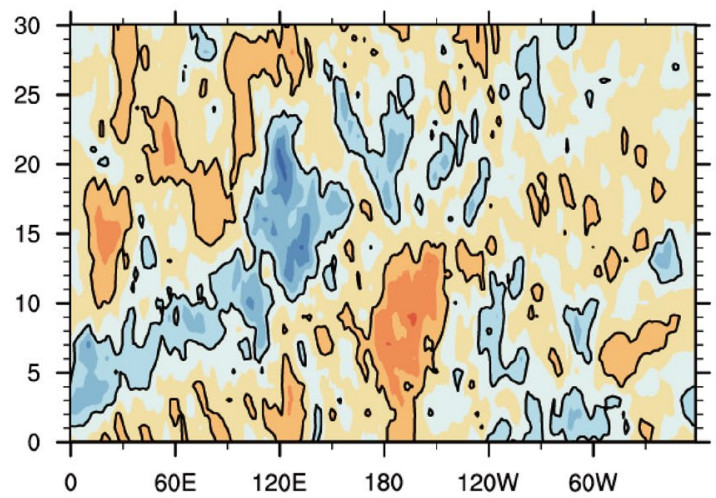

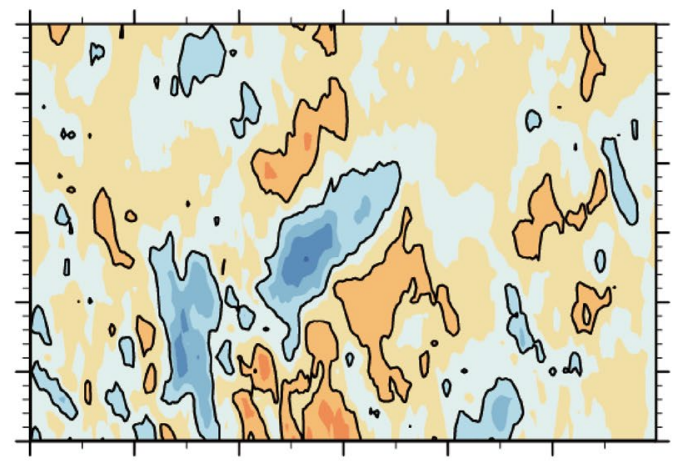
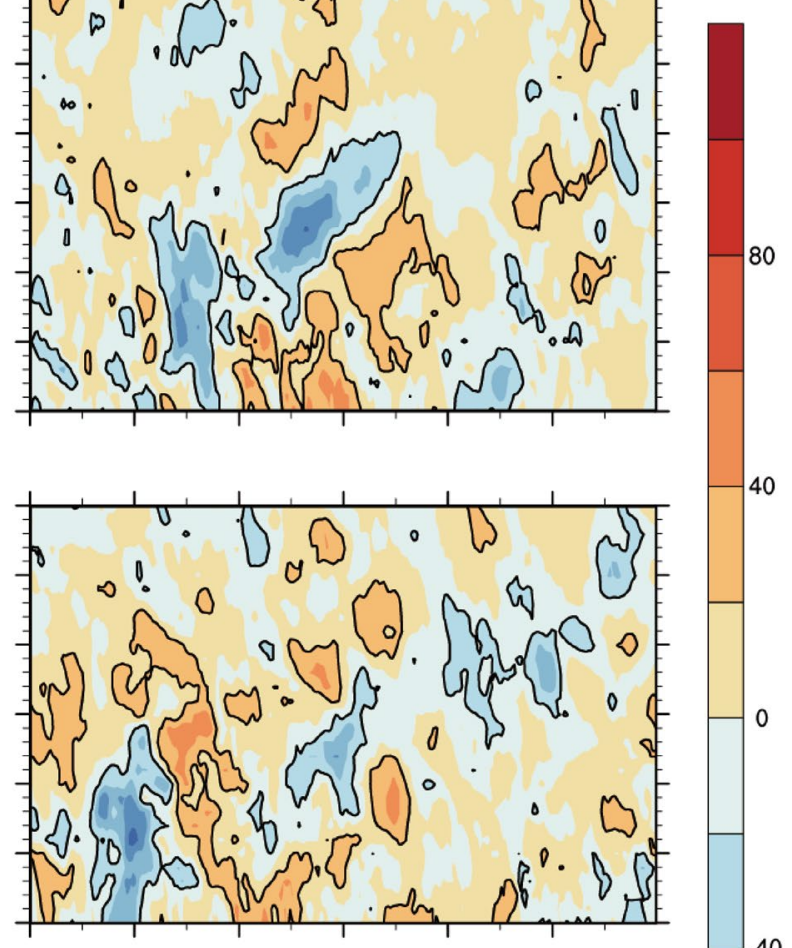

40

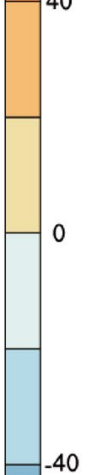

$-40$

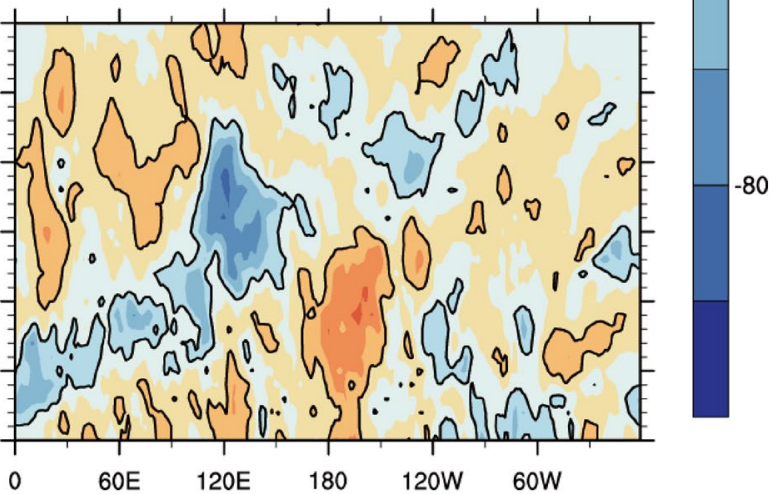

Fig. 8 (continued)

MSE tendency due to the horizontal advection, making the recharge and discharge of the column MSE more gradual than if horizontal advection were acting alone. Moreover, Andersen and Kuang (2012) analyzed the MSE budget of MJO-like disturbances to explore the processes of its propagation and maintenance. Arnold et al. (2013) used the MSE budgets analysis to diagnose the physical processes responsible for the relationship of an MJO-like variability against SST. Therefore, we explore the dominant mechanism contributing to the SV growth based on the MSE budget analysis, as it has been used widely in several MJO studies recently, as stated above.

The MSE (denoted by $h$ ) is usually defined as follows: $h=c_{p} T+g z+L q$

where $C_{p}$ is the specific heat at constant pressure of dry air, $T$ is the temperature, $g$ is the gravitational acceleration, $z$ is the geopotential height, $L$ is the latent heat of vaporization, and $q$ is the specific humidity.

We analyzed the column integrated MSE budget following Neelin and Held's study (1987):

$\left\langle\frac{\partial h}{\partial t}\right\rangle=-\langle\vec{V} \cdot \nabla h\rangle-\left\langle\omega \cdot \frac{\partial h}{\partial p}\right\rangle+L H+S H+\langle L W\rangle+\langle S W\rangle$ 


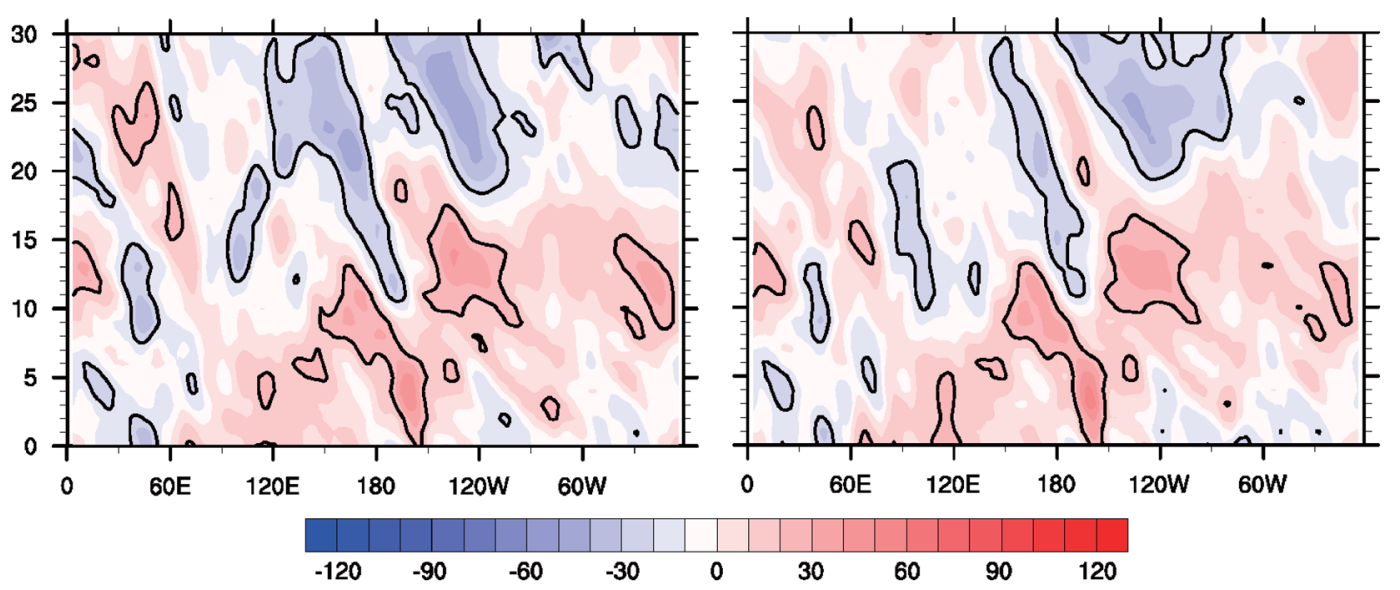

Fig. 9 Hovmoller diagram of intraseasonal MSE tendency $\left(\mathrm{J} \mathrm{kg}^{-1} \mathrm{~s}^{-1}\right)$ for original simulation (left) and simulation under initial condition superimposed with leading SV (right). Anomalies above 20 $\mathrm{J} \mathrm{kg}^{-1} \mathrm{~s}^{-1}$ and below $-20 \mathrm{~J} \mathrm{~kg}^{-1} \mathrm{~s}^{-1}$ are contoured. First, each column integrated MSE budget term is calculated according to Eq. (10).

where the angular brackets $<>$ indicate a vertical massweighted integral from $100 \mathrm{hPa}$ to the surface, $\vec{V}$ is the horizontal wind vector, $\omega$ is the pressure velocity, and $L H$ and $S H$ represent the surface latent and sensible heat flux, respectively. $L W$ and $S W$ are the net long wave and short wave heating rates, respectively.

Therefore, the term on the left hand side of Eq. (9) represents the column integration of the MSE tendency, and the first and second terms on the right hand side indicate the horizontal and vertical advection of the MSE.

In this study, we focused on the MSE budget on the MJO scale, which is expressed as

$$
\begin{aligned}
\left\langle\frac{\partial h}{\partial t}\right\rangle_{\mathrm{MJO}}= & -\langle\vec{V} \cdot \nabla h\rangle_{\mathrm{MJO}}-\left\langle\omega \cdot \frac{\partial h}{\partial p}\right\rangle_{\mathrm{MJO}}+L H_{\mathrm{MJO}} \\
& +S H_{\mathrm{MJO}}+\langle L W\rangle_{\mathrm{MJO}}+\langle S W\rangle_{\mathrm{MJO}}
\end{aligned}
$$

The subscript MJO indicates the MJO scale (wavenumbers of 1-3, periods of 20-100 days), which was filtered following the method introduced by Lin et al. (2008). The term $\langle S W\rangle_{\mathrm{MJO}}$ in Eq. (10) was ignored in the following analysis because of its negligible amount compared to the other terms (not shown), which was also stated by Maloney (2009).

First, each integrated MSE budget term was calculated according to Eq. (10). Second, the meridional values were averaged between $10^{\circ} \mathrm{S}$ and $10^{\circ} \mathrm{N}$. Finally, the intraseasonal MSE budget terms over the tropics are obtained following the method mentioned above. To further explore the development of the intraseasonal OLR anomalies, the MSE budget was also analyzed by the Hovmoller diagram. As such, the dominant MSE budget term responsible for the development of the MJO may be shed on lights.
Second, meridional values between $10^{\circ} \mathrm{S}$ and $10^{\circ} \mathrm{N}$ are averaged. Finally, intraseasonal MSE budget terms over tropics are obtained following method introduced by Lin et al. (2008). Seven-point running average is performed to make diagram clearer and more intuitive

We considered Case 1 as an example to examine the budget terms on the right hand side of Eq. (10) because all the six cases display similar results (not shown). Figure 9 presents the Hovmoller diagrams of the intraseasonal MSE tendency [the item on the left hand side of Eq. (10)] for experiments woSV and wSV. The positive MSE tendency displays evident eastward propagation from the Indian Ocean at the initial time to the Pacific Ocean after 30 days. By comparing Fig. 9 with Fig. 8, we found that the positive anomalies of the intraseasonal MSE are ahead of the deep convection (i.e., negative intraseasonal OLR anomalies) by approximately five days. That is, the increased MSE can be considered a necessary condition for deep convection, which agrees with Li's (2014) and Maloney's (2009) studies.

Next, the mechanism of the MJO was investigated by analyzing the dominant MSE budget term responsible for the development of the MJO. The results are presented in Fig. 10. In the figure, the terms $L H_{\mathrm{MJO}}$ and $S H_{\mathrm{MJO}}$ are summed, as the magnitude of $L H_{\mathrm{MJO}}$ is an order larger than $S H_{\mathrm{MJO}}$ (Maloney 2009). Therefore, only four MSE budget terms were compared between experiments woSV (Fig. 10a) and wSV (Fig. 10b). The strong positive heat flux near $120^{\circ}$ $\mathrm{E}$ appeared at approximately day 5, whereas other terms as well as the deep convection depicted in Fig. 10 began from approximately day 10 . This result indicates that the positive anomaly of the heat flux preconditions the eastward propagation of the $\mathrm{MJO}$, consistent with the observation analysis (e.g., Sobel et al. 2014) and model results (e.g., Maloney 2009).

Comparing the budget terms of experiments wSV and woSV revealed possible mechanisms for optimal error growth. For Case 1, the negative anomalies of horizontal advection in the $\mathrm{IO}$ and the $\mathrm{MC}$ were weaker in experiment 
(a)
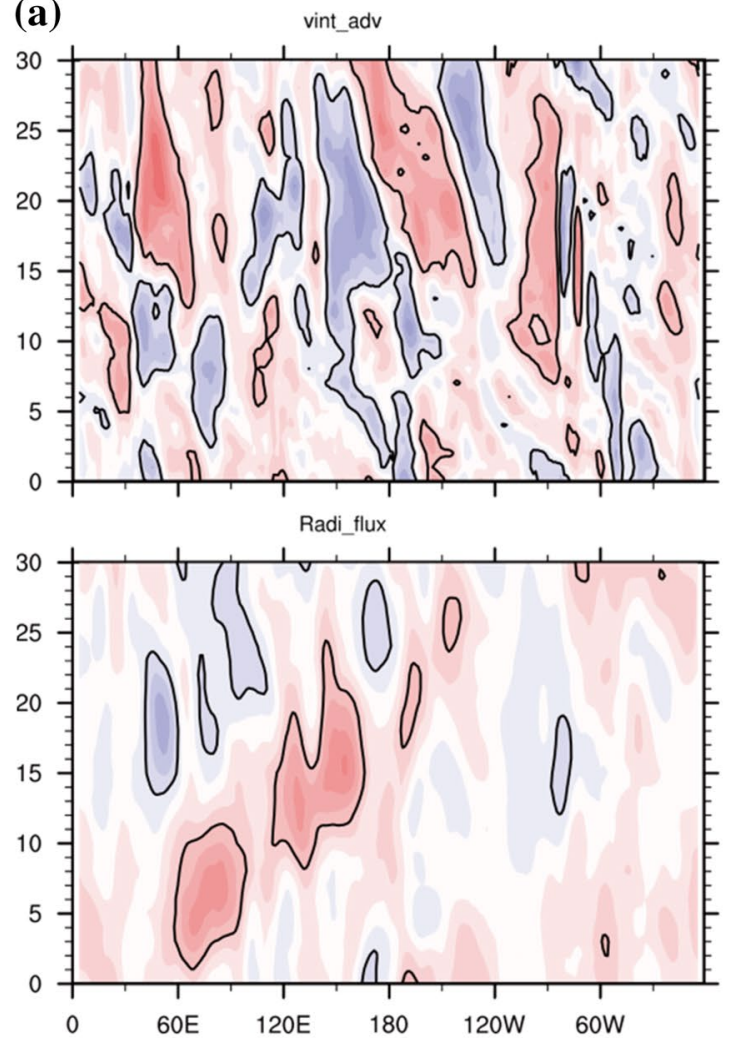

(b)
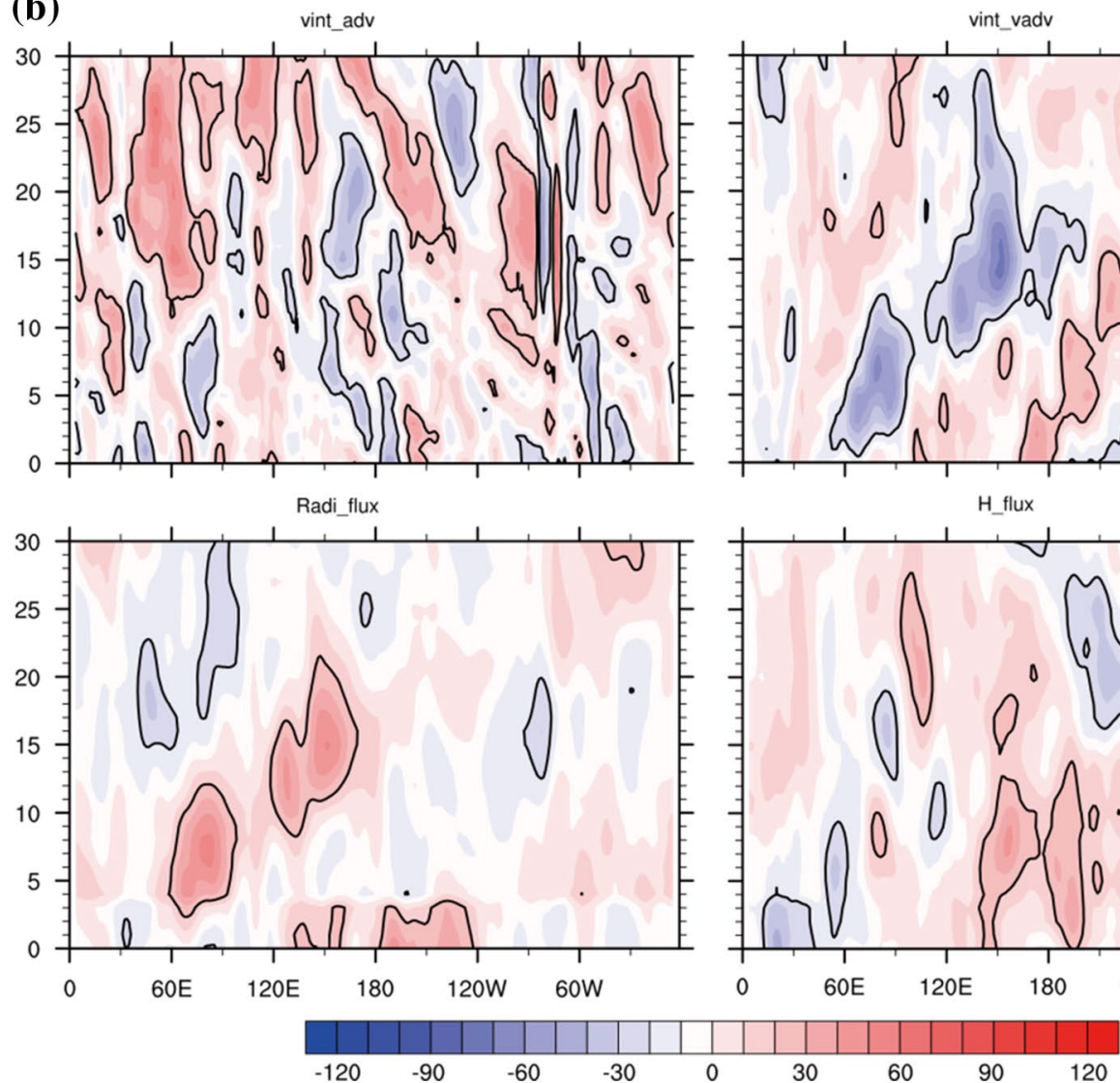

vint vadv
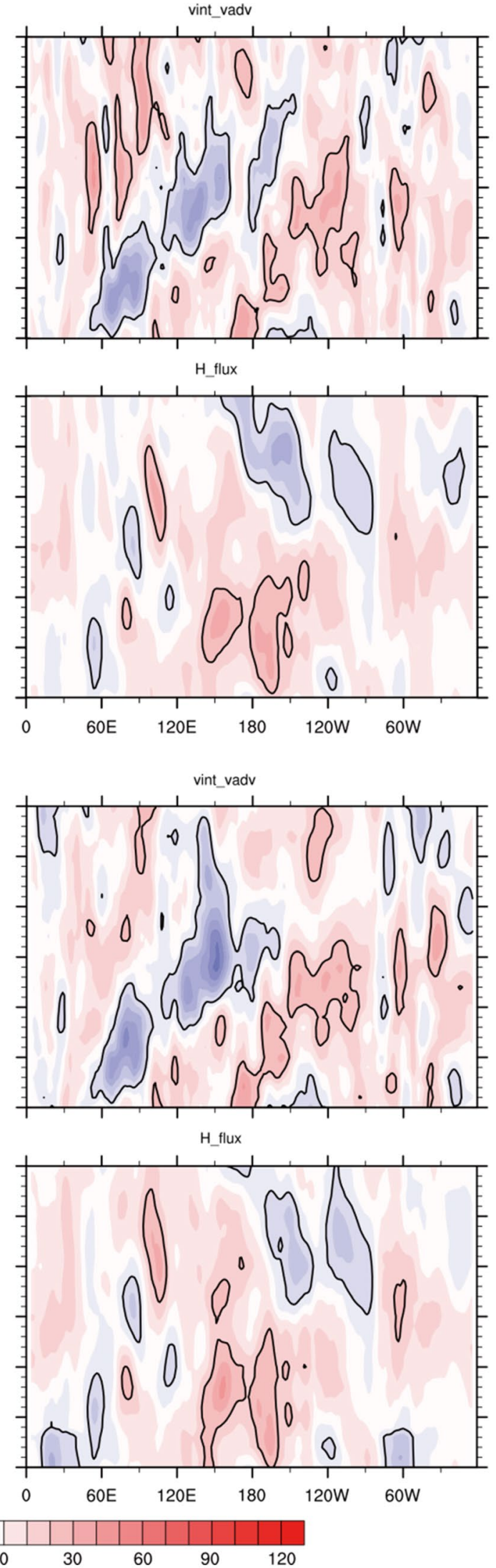
४Fig. 10 Same as Fig. 9 except that terms specified are right hand side of Eq. (10) for original simulation (a) and simulation under initial SST condition with leading singular vector perturbation $(\mathbf{b})$. Title names "vint_adv", "vint_vadv", "Radi_flux", "H_flux" are short for vertical integral of horizontal advection, vertical integral of vertical advection, radiation flux, and heat flux, respectively. Radiation flux term essentially refers to long-wave radiation, as short-wave radiation is negligible compared to other terms. Heat flux term includes sum of latent and sensitive heat fluxes

wSV than those in experiment woSV indicating that the SV perturbation inhibits the horizontal advection of the column. The negative anomalies in the vertical advection term were stronger in experiment wSV than those in experiment woSV. Further, the radiation flux term was somewhat weaker after entering the Pacific Ocean in experiment wSV. As for the heat flux term (including latent and sensible heat fluxes), the positive anomalies in the Indian Ocean and the Maritime Continent (approximately $60^{\circ} \mathrm{E}-150^{\circ} \mathrm{E}$ ) were slightly stronger in experiment $\mathrm{wSV}$ than those in experiment woSV.

As depicted in Fig. 10, the eastward propagation, a significant MJO feature, is much more evident in the vertical advection and radiation flux terms than that in the other two terms. Therefore, we only focused on these two terms for the other five MJO cases to investigate the error growth owing to the SV perturbation. Figure 11 presents the results for the other cases. It can be seen that the SV perturbation led to higher convergence and increase in the negative anomalies of vertical advection, particularly 10 days after the initial time, in all these cases, which is the same as the result in Case 1. This result agree with the study in Arnold et al. (2013), where they found that increasing SST leads to an increasingly positive contribution from vertical advection to the MSE. However, its effect on the positive anomalies of radiation flux is inconsistent for the six cases. For instance, the positive anomalies of radiation flux were strengthened in Cases 1,2, and 3 but weakened in Cases 4, 5, and 6 by the SV perturbation. Therefore the SV, as the optimal perturbation, can lead to a more converged and stronger MJO signal mainly by increasing vertical advection of the MSE. The effect of the radiation processes is dependent on specific initial conditions.

\section{Summary and discussions}

In this study, we investigated the optimal growth of the MJO forecast error that originates from uncertainties in the SST of the Indian Ocean by applying the CSV method. The CSV method is based on an ensemble strategy, and it is more computationally efficient than the conventional singular vector method, as the tangent model is not required in the
CSV method, which is difficult to provide in the fully coupled model CESM. Moreover, the CSV method can filter out weather noise contained in any global coupled models with multiscale processes, so that only the dynamic and physical processes responsible for climate variability can be addressed. In this study, we focused on the optimal growth of the MJO prediction error arising from the MJO phase II, i.e., when the deep convection is located in the Indian Ocean. To obtain robust results, we chose six different MJO cases with various initial SST conditions. In addition, the sensitivity of the leading SV to the initial SST structure was explored. Finally, we applied the MSE budget analysis to investigate the possible mechanism and dominant contributors responsible for the optimal growth of the SV perturbation, considering the importance of MSE in the MJO propagation.

The leading SVs for all the six study cases resemble each other, which is a meridional dipole-like pattern with the opposite maximum values located in the Bay of Bengal and in the central south Indian Ocean. This indicates that the leading SV of the MJO is not sensitive to the spatial distribution of the initial SSTA. With the initial SST superimposed on the leading SV, the model can produce a more converged and stronger MJO signal in the Eastern Hemisphere, particularly after crossing $120^{\circ} \mathrm{E}$. Based on the MSE budget analysis, the converged and stronger MJO signal caused by the SV perturbation is attributed primarily to the increase in vertical advection of the MSE. The MSE analysis reveals that the positive anomaly of the heat flux develops approximately five days ahead of the strengthening convection, indicating the precondition effect of the positive heat flux anomaly on the eastward propagation. Among all the budget terms, the vertical advection and radiation flux terms contribute the most to the MJO propagation. The SV perturbation also inhibits the horizontal advection of the column.

This work is the first attempt to study the influence of SST on the MJO in the framework of predictability. Some interesting results and findings have been obtained, which can shed light on significant issues in the study of MJO prediction. The SVs of the MJO obtained in this study provide a direct means by which MJO ensemble prediction can be performed, which is practically significant. In particular, sensitivity studies indicate that the leading SV is not very sensitive to the initial SST, suggesting that in constructing the ensemble prediction, we might not need to calculate SVs for each initial time. This provides a computationally efficient scheme for an ensemble prediction system.

As we know, the MJO is a coupled mode in the tropics, spanning from the Indian Ocean to the Pacific Ocean during its life cycle. Therefore, it is of notable research interest to explore the optimal initial perturbation in the Pacific Ocean 
Fig. 11 Same as Fig. 10 except that only vertical advection (vint_vadv) and radiation terms (Radi_flux) are specified for experiments woSV (left) and wSV (right) in Cases 2 (a), 3 (b), 4 (c), 5 (d), and 6 (e) (a) CASE 2
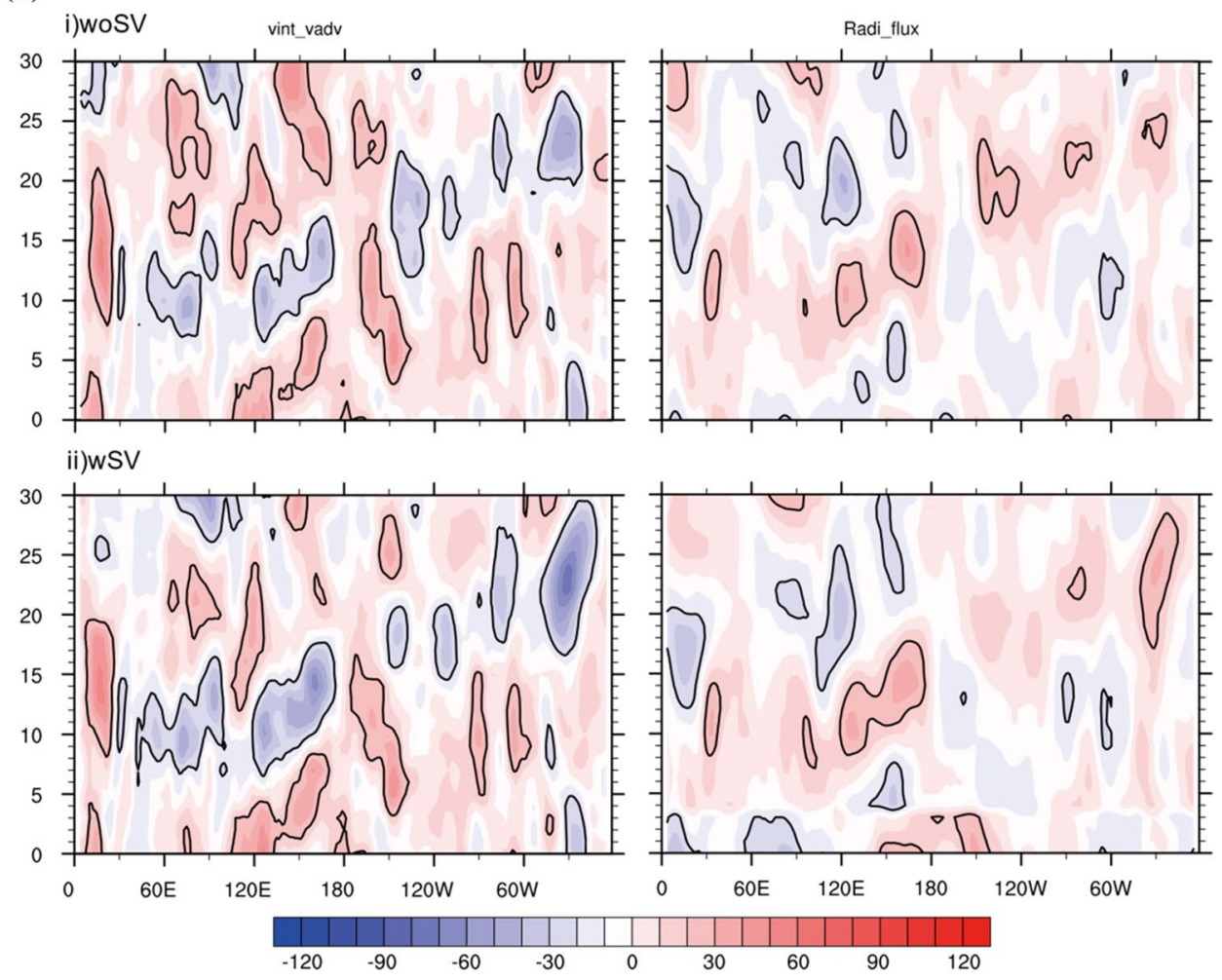

(b) CASE 3
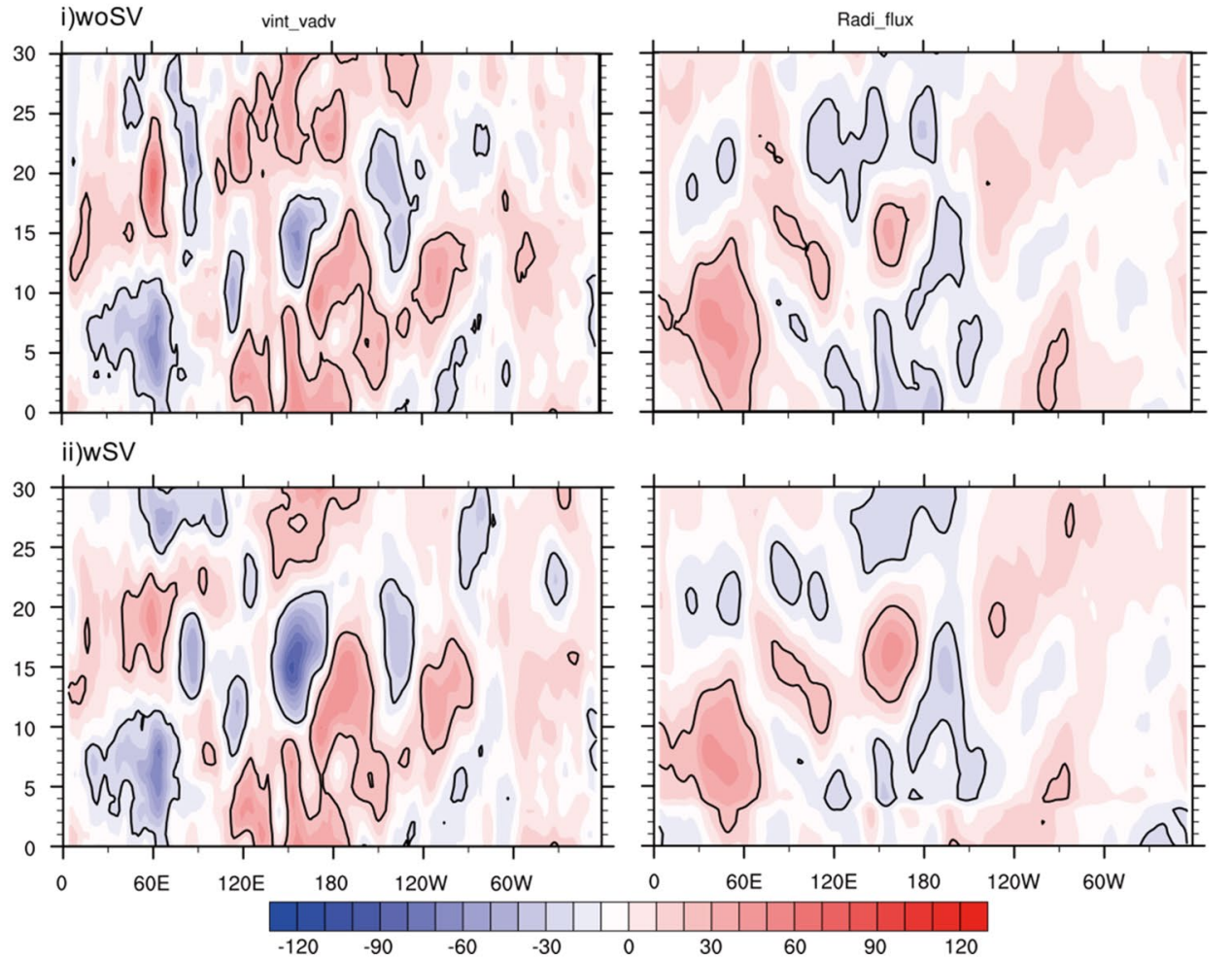
Fig. 11 (continued)

(c) CASE 4
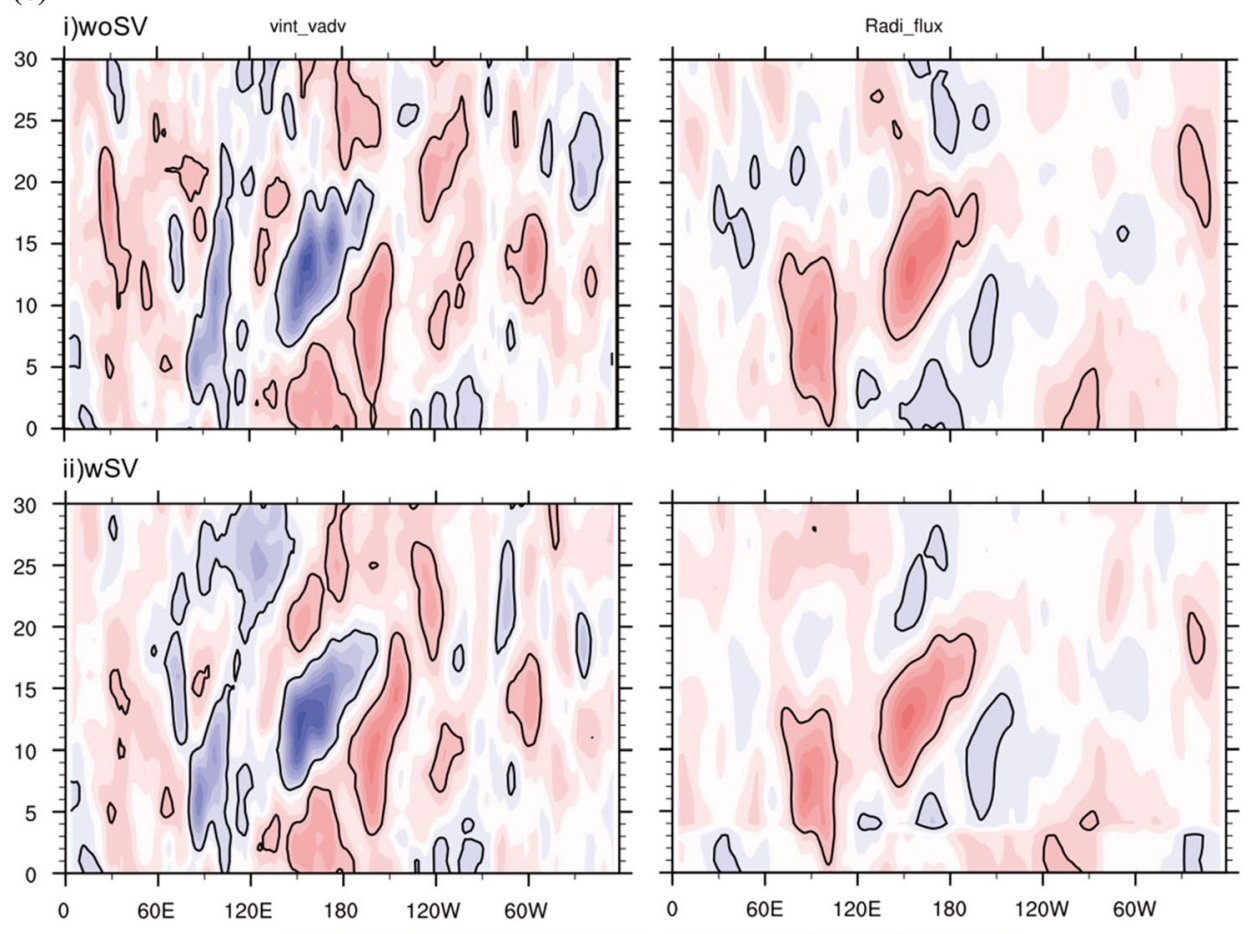

(d) CASE 5
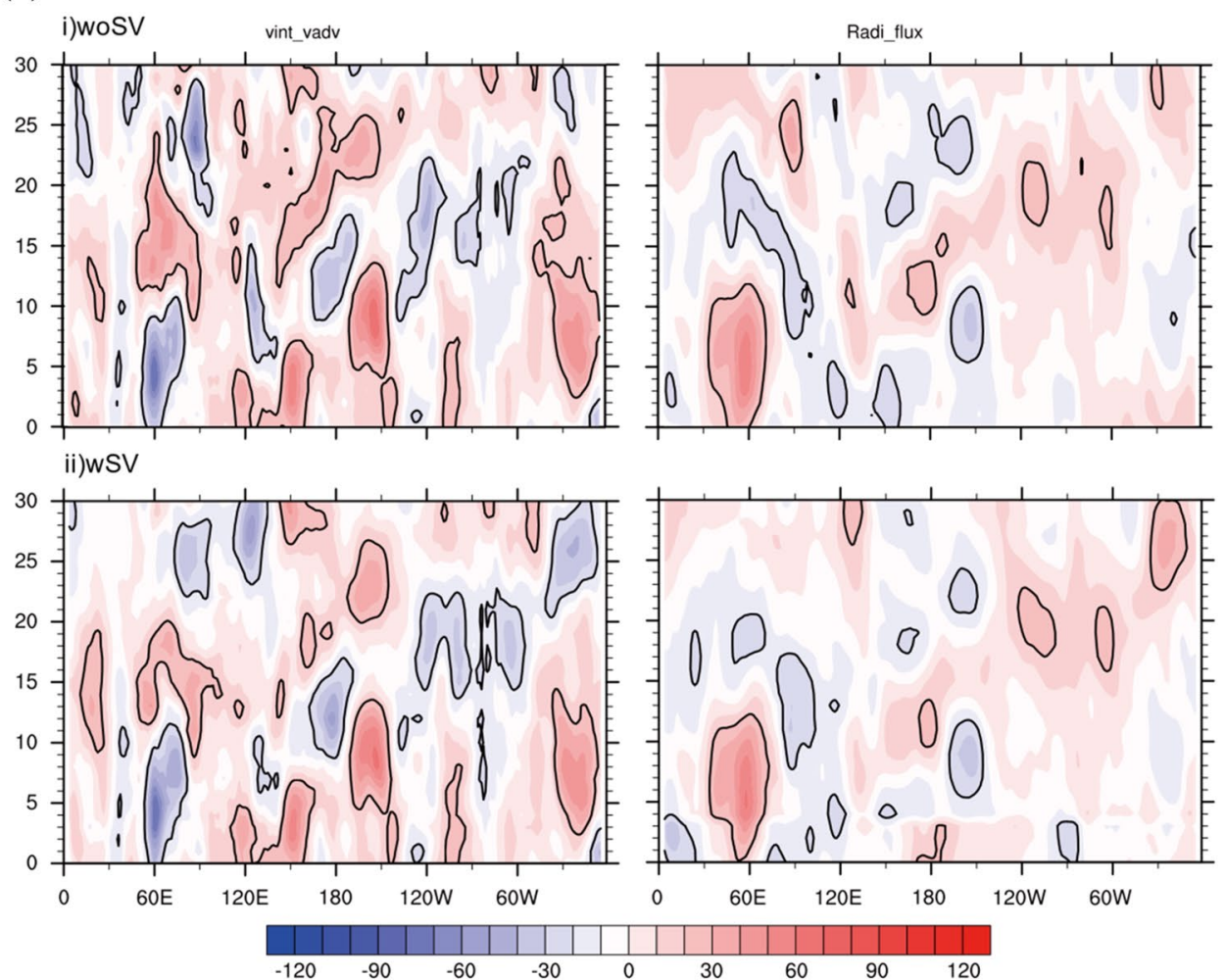
Fig. 11 (continued)

(e) CASE 6
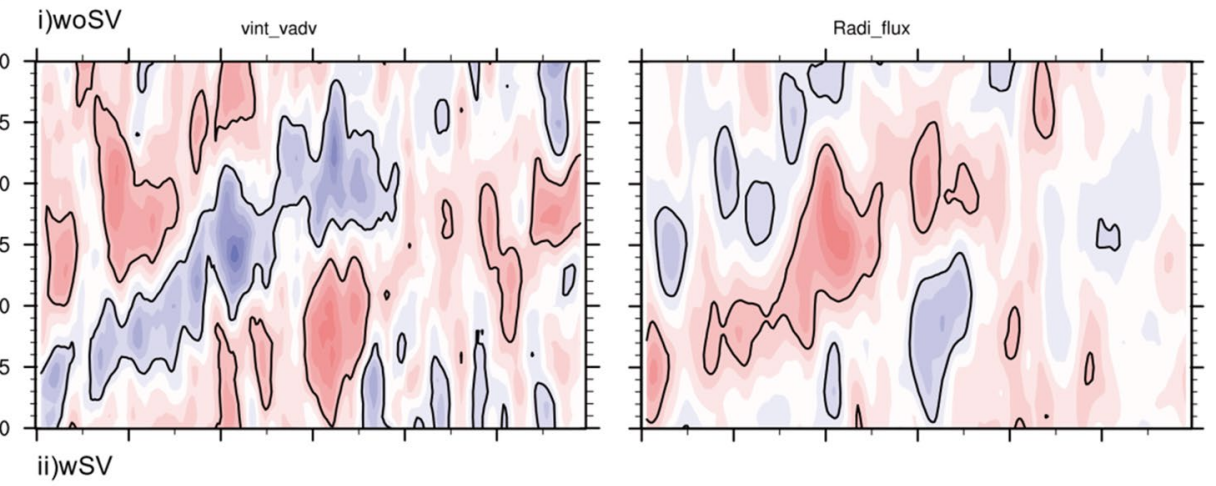

ii)wSV
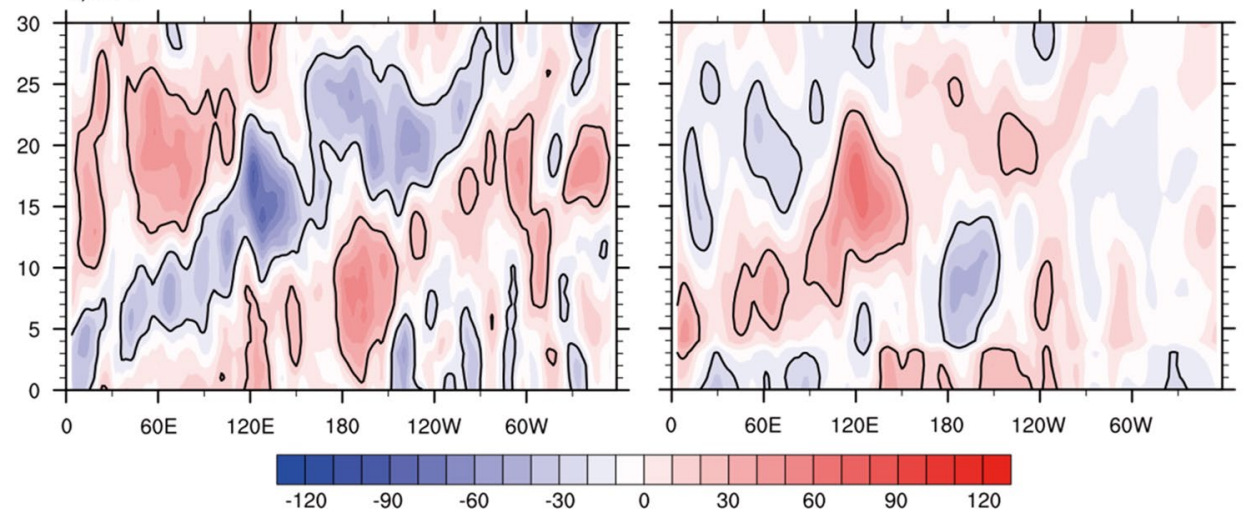

and the Indo-Pacific Ocean. And our findings may elucidate further research in this field.

Acknowledgements This work is supported by Grants from the National Key R\&D Program of China (2017YFA0604202), National Program on Global Change and Air-Sea Interaction (GASI-IPOVAI-06), Scientific Research Fund of the Second Institute of Oceanography, MNR (JG1617), and National Natural Science Foundation of China (41706009, 41530961, and 41621064).

Open Access This article is licensed under a Creative Commons Attribution 4.0 International License, which permits use, sharing, adaptation, distribution and reproduction in any medium or format, as long as you give appropriate credit to the original author(s) and the source, provide a link to the Creative Commons licence, and indicate if changes were made. The images or other third party material in this article are included in the article's Creative Commons licence, unless indicated otherwise in a credit line to the material. If material is not included in the article's Creative Commons licence and your intended use is not permitted by statutory regulation or exceeds the permitted use, you will need to obtain permission directly from the copyright holder. To view a copy of this licence, visit http://creativecommons.org/licenses/by/4.0/.

\section{References}

Agudelo PA, Curry JA, Hoyos CD, Webster PJ (2006) Transition between suppressed and active phases of intraseasonal oscillations in the indo-pacific warm pool. J Clim 19:5519-5530

Ahn MS, Kim D, Sperber KR, Kang IS, Maloney E, Waliser D, Hendon H (2017) MJO simulation in CMIP5 climate models:MJO skill metrics and process-oriented diagnosis. Clim Dyn 49(11-12):4023-4045

Andersen JA, Kuang Z (2012) Moist static energy budget of MJO-like disturbances in the atmosphere of a zonally symmetric aquaplanet. J Clim 25(8):2782-2804

Arkin PA, Ardanuy PE (1989) Estimating climatic-scale precipitation from space: a review. J Clim 2(11):1229-1238

Arnold NP, Kuang Z, Tziperman E (2013) Enhanced MJO-like variability at high SST. J Clim 26(3):988-1001

Bai XX, Li CY, Tan YK, Guan ZJ (2013) The impacts of MaddenJulian Oscillation on spring rainfall in East China. J Trop Meteorol 19:214-222

Barnett TP, Preisendorfer R (1987) Origins and levels of monthly and seasonal forecast skill for United States surface air temperatures determined by canonical correlation analysis. Mon Weather Rev 115(9):1825-1850

Barnston AG, Tippett MK, Ranganathan M, L'Heureux ML (2017) Deterministic skill of ENSO predictions from the North American Multimodel Ensemble. Clim Dyn. https://doi.org/10.1007/s0038 2-017-3603-3

Bauer P, Thorpe A, Brunet G (2015) The quiet revolution of numerical weather prediction. Nature 525:47-55

Buizza R (1995) Optimal perturbation time evolution and sensitivity of ensemble prediction to perturbation amplitude. Q J R Meteorol Soc 121:1705-1738

Buizza R (1997) Potential forecast skill of ensemble prediction and spread and skill distributions of the ECMWF ensemble prediction system. Mon Weather Rev 125(1):99-119

Ding RQ, Li JP, Seo KH (2010) Predictability of the madden-julian oscillation estimated using observational data. Mon Weather Rev 138:1004-1013 
Ding RQ, Li JP, Seo KH (2011) Estimate of the predictability of boreal summer and winter intraseasonal oscillations from observations. Mon Weather Rev 139:2421-2438

Evans S, Marchand R, Ackerman T (2014) Variability of the Australian Monsoon and precipitation trends at Darwin. J Clim 27:8487-8500

Farrell BF, Ioannou PJ (2001) Accurate low-dimensional approximation of the linear dynamics of fluid flow. J Atmos Sci 58:2771-2789

Fu XH, Yang B, Bao Q, Wang B (2008) Sea surface temperature feedback extends the predictability of tropical intraseasonal oscillation. Mon Weather Rev 136:577-597

Fu X, Lee J-Y, Hsu P-C, Taniguchi H, Wang B, Wang W, Weaver S (2013) Multi-model MJO forecasting during DYNAMO/CINDY period. Clim Dyn 41:1067-1081

Han W, Yuan D, Liu WT, Halkides DJ (2007) Intraseasonal variability of Indian Ocean sea surface temperature during boreal winter: Madden-Julian Oscillation versus submonthly forcing and processes. J Geophys Res 112:C04001. https://doi.org/10.1029/2006J C003791

Hawkins E, Sutton R (2011) The potential to narrow uncertainty in projections of regional precipitation change. Clim Dyn 37:407-418

Hoell A, Barlow M, Wheeler MC, Funk C (2014) Disruptions of El Nino-Southern Oscillation Teleconnections by the MaddenJulian Oscillation. Geophys Res Lett 41:998-1004

Islam SU, Tang Y, Jackson PL (2016) Optimal error growth of South Asian monsoon forecast associated with the uncertainties in the sea surface temperature. Clim Dyn 46:1953-1975

Jin EK, Kinter JL, Wang B, Park CK, Kang I-S, Kirtman BP, Kug J-S, Kumar A, Luo J-J, Schemm J, Shukla J, Yamagata T (2008) Current status of ENSO prediction skill in coupled ocean-atmosphere models. Clim Dyn 31:647-664

Kalnay E, Dalcher A (1987) Forecasting forecast skill. Mon Weather Rev 115(2):349-356

Kang IS, Kim HM (2010) Assessment of MJO predictability for boreal winter with various statistical and dynamical models. J Clim 23(9):2368-2378

Kiladis GN, Straub KH, Haertel PT (2005) Zonal and vertical structure of the Madden-Julian oscillation. J Atmos Sci 62(8):2790-2809

Kim HM, Webster PJ, Toma VE, Kim D (2014) Predictability and prediction skill of the MJO in two operational forecasting systems. J Clim 27(14):5364-5378

Kleeman R, Tang YM, Moore AM (2003) The calculation of climatically relevant singular vectors in the presence of weather noise as applied to the ENSO problem. J Atmos Sci 60:2856-2868

Leith CE, Kraichnan RH (1972) Predictability of turbulent flows. J Atmos Sci 29(6):1041-1058

Li T (2014) Recent advance in understanding the dynamics of the Madden-Julian oscillation. Acta Meteorol Sin 28(1):1-33

Li X, Tang Y, Zhou L, Chen D, Yao Z, Islam SU (2016) Assessment of Madden-Julian oscillation simulations with various configurations of CESM. Clim Dyn 47:2667-2690

Lin H, Brunet G, Derome J (2008) Forecast skill of the Madden-Julian oscillation in two Canadian atmospheric models. Mon Weather Rev 136:4130-4149

Lin H, Brunet G, Mo RP (2010) Impact of the Madden-Julian oscillation on wintertime precipitation in Canada. Mon Weather Rev 138:3822-3839

Lorenz EN (1969) The predictability of a flow which possesses many scales of motion. Tellus 21(3):289-307

Lorenz EN (1993) The essence of chaos. University of Washington Press, Seattle

Maloney E (2009) The moist static energy budget of a composite tropical intraseasonal oscillation in a climate model. J Clim 22:711-729

Marshall AG, Hendon HH, Wang G (2016) On the role of anomalous ocean surface temperatures for promoting the record
Madden-Julian Oscillation in March 2015. Geophys Res Lett 43:472-481

Matthews AJ (2000) Propagation mechanisms for the Madden-Julian oscillation. Q J R Meteorol Soc 126(569):2637-2651

Matthews AJ (2008) Primary and successive events in the MaddenJulian Oscillation. Q J R Meteorol Soc 134:439-453

Moon J, Wang B, Kwon WT (2007) The response of northern hemisphere atmospheric circulation to the northward migration of tropical forcing. J Korean Meteorol Soc 43:253-265

Moore AM, Kleeman R (1996) The dynamics of error growth and predictability in a coupled model of ENSO. Q J R Meteorol Soc 122:1405-1446

Moore AM, Kleeman R (2001) The differences between the optimal perturbations of coupled models of ENSO. J Clim 14:138-163

Mu M, Duan W, Wang B (2007) Season-dependent dynamics of nonlinear optimal error growth and El Niño-Southern Oscillation predictability in a theoretical model. J Geophys Res 112:D10113. https://doi.org/10.1029/2005JD006981

Neelin J, Held I, Cook K (1987) Evaporation-wind feedback and lowfrequency variability in the tropical atmosphere. J Atmos Sci 44:2341-2348

Palmer TN (2000) Predicting uncertainty in forecasts of weather and climate. Rep Prog Phys 63:71-116

Palmer TN, Tibaldi S (1988) On the prediction of forecast skill. Mon Weather Rev 116(12):2453-2480

Palmer TN, Zanna L (2013) Singular vectors, predictability and ensemble forecasting for weather and climate. J Phys A: Math Theor 46:254018

Palmer TN, Buizza R, Molteni F, Chen YQ, Corti S (1994) Singular vectors and the predictability of weather and climate. Philos Trans R Soc Lond Ser A Phys Eng Sci 348(1688):459-475

Palmer TN, Döring A, Seregin G (2014) The real butterfly effect. Nonlinearity 27(9):R123-R141

Raymond D (2001) A new model of the Madden-Julian Oscillation. J Atmos Sci 58:2807-2819

Sobel AH, Gildor H (2003) A simple time-dependent model of SST hot spots. J Clim 16:3978-3992

Sobel A, Wang S, Kim D (2014) Moist static energy budget of the MJO during DYNAMO. J Atmos Sci 71:4276-4291

Subramanian AC, Jochum M, Miller AJ, Murtugudde R, Neale RB, Waliser DE (2011) The Madden-Julian Oscillation in CCSM4. J Clim 24:6261-6282

Tang Y, Yu B (2008) MJO and its relationship to ENSO. J Geophys Res 113:D14106. https://doi.org/10.1029/2007JD009230

Tang Y, Kleeman R, Miller S (2006) ENSO predictability of a fully coupled GCM Model using singular vector analysis. J Clim 19:3361-3377

Toth Z, Kalnay E (1997) Ensemble forecasting at NCEP and the breeding method. Mon Weather Rev 125(12):3297-3319

Vialard J, Foltz GR, McPhaden MJ, Duvel JP, de Boyer MC (2008) Strong Indian Ocean sea surface temperature signals associated with the Madden-Julian Oscillation in late 2007 and early 2008. Geophys Res Lett 35:L19608. https://doi.org/10.1029/2008G L035238

Waliser DE, Lau KM, Stern W, Jones C (2003) Potential predictability of the Madden-Julian oscillation. Bull Am ol Soc 84(1):33-50

Wang B, Lee J, Kang I-S, Shukla J, Park C-K, Kumar A, Schemm J, Cocke S, Kug J-S, Luo J-J, Zhou T, Wang B, Fu X, Yun W-T, Alves O, Jin EK, Kinter J, Kirtman B, Krishnamurti T, Lao NC, Lau W, Liu P, Pegion P, Rosati T, Schubert S, Stern W, Suarez M, Yamagata T (2009) Advance and prospectus of seasonal prediction: assessment of the APCC/CliPAS 14-model ensemble retrospective seasonal prediction (1980-2004). Clim Dyn 33:93-117

Wang WQ, Hung MP, Weaver SJ, Kumar A, Fu XH (2014) MJO prediction in the NCEP climate forecast system version 2. Clim Dyn 42:2509-2520 
Weisman ML, Davis C, Wang W, Manning KW, Klemp JB (2010) Experiences with 0-36-h explicit convective forecasts with the WRF-ARW model. Weather Forecast 23:407-437

Wheeler MC, Hendon HH (2004) An all-season real-time multivariate MJO index: development of an index for monitoring and prediction. Mon Weather Rev 132:1917-1932

Wobus RL, Kalnay E (1995) Three years of operational prediction of forecast skill at NMC. Mon Weather Rev 123(7):2132-2148
Yuan Y, Yang H, Li C (2014) Possible influences of the tropical Indian Ocean dipole on the eastward propagation of MJO. J Trop Meteor 28:735-742 (in Chinese)

Publisher's Note Springer Nature remains neutral with regard to jurisdictional claims in published maps and institutional affiliations. 